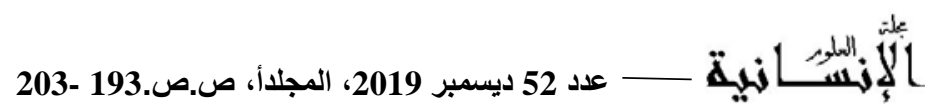

\title{
وضعية الأملاك الوقفية في الجزائر قبل صدور دستور 1989
}

The Role of Waqf Properties in Algeria before the 1989 Constitution

تاريخ الاستلام : 2019/11/19 ؛ تاريخ القبول : 2019/12/10

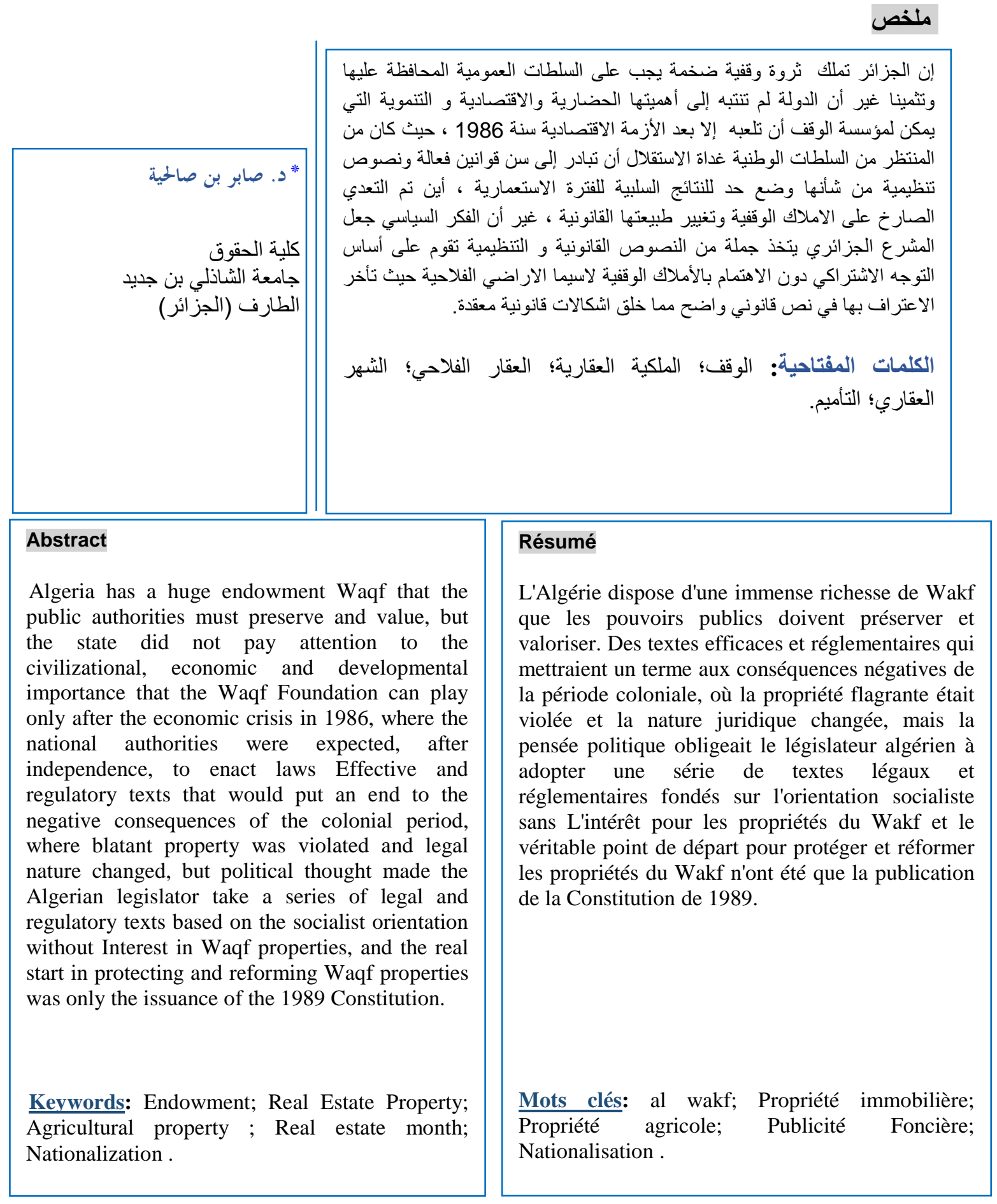

*Corresponding author, e-mail: bensalhiasaber@gmail.com 


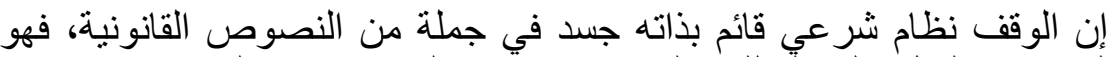

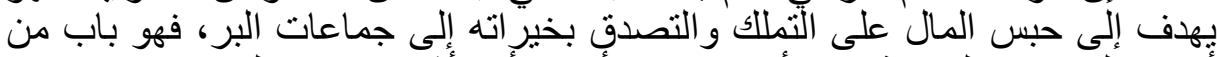

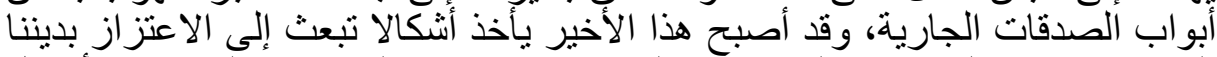

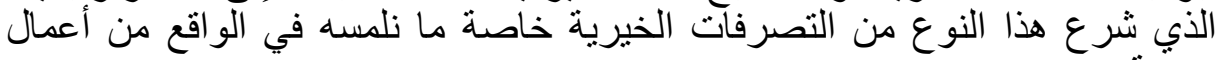

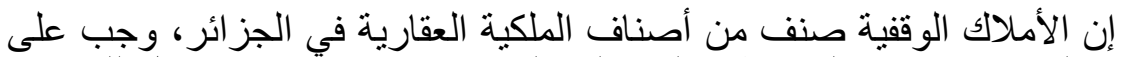

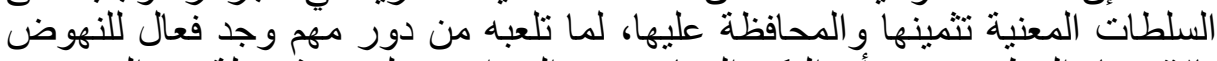

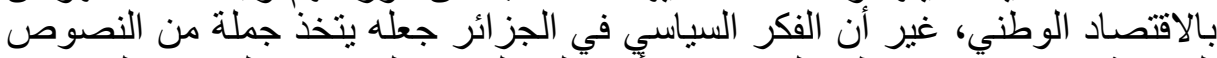

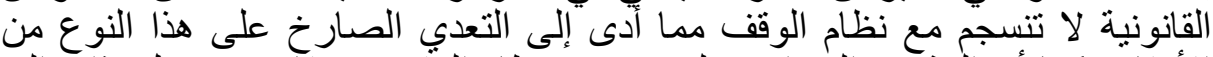

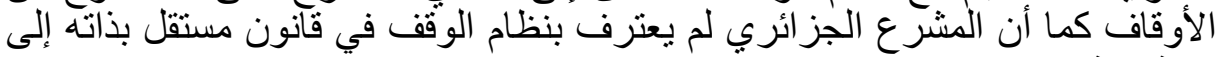

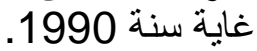

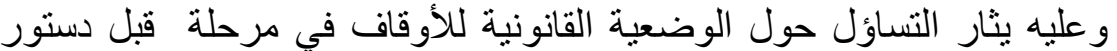

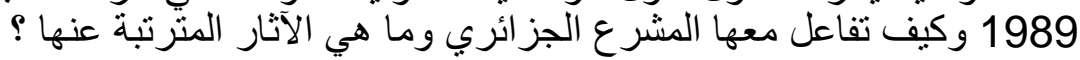

ولإجابة على هذه التساؤلات تم تقسيم الموضوع إلى ثلاث الألى مطالب أساسية،

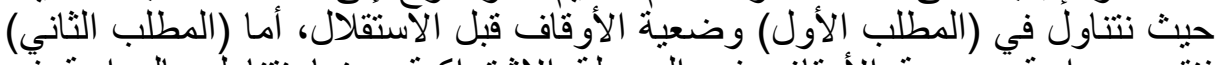

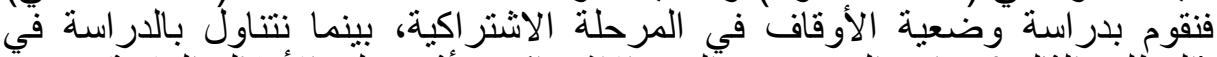

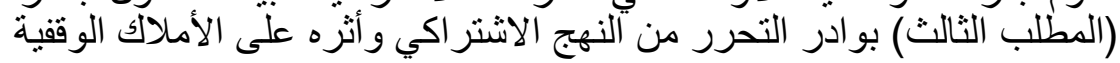

\section{المطلب الاول: وضعية الأوقاف قبل الاستقلال:}

لقد خضعت الأوقاف مند الفتوحات الأولى إلى أحكام الثريعة الإسلامية

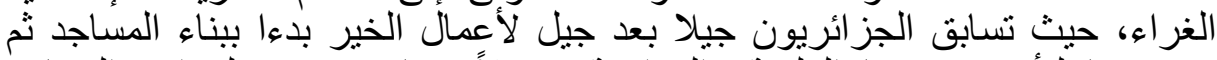

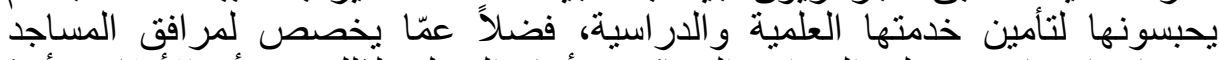

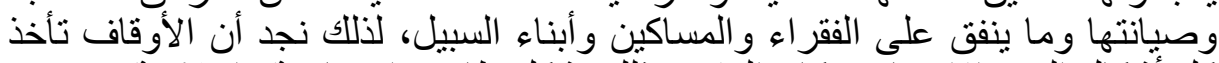
كل أثكال البر والإحسان، فكان الوقف بذلك يشكل ظاهرة اجتماعية وإسلامية متميزة الأن

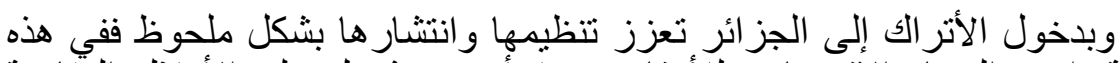

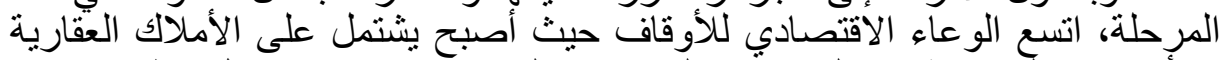

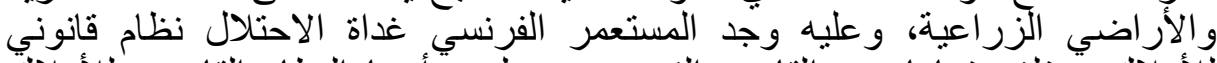

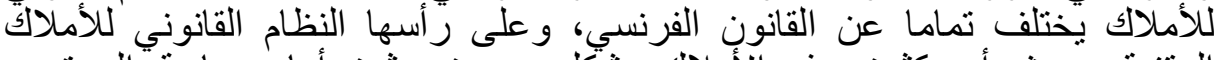

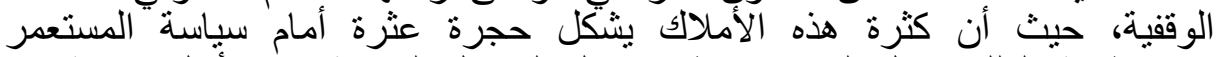

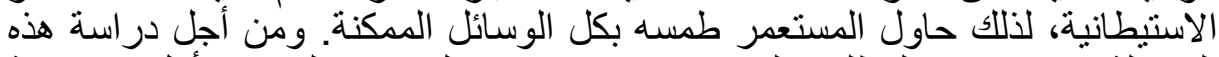

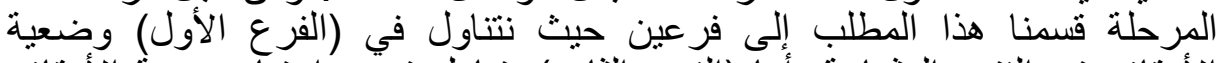

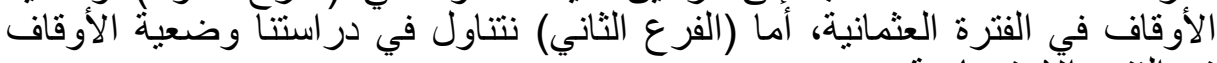

$$
\text { في الفترة الآستعمارية }
$$

\section{الفرع الأول: وضعية الأوقاف في الفترة العثمانية :}

لقد استمرت الأملاك الوقفية في الانتشار طيلة الفترة العثمانية حتى أصبحت

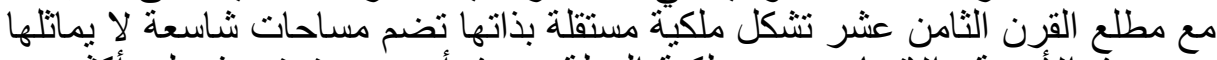

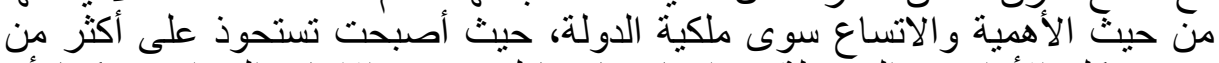

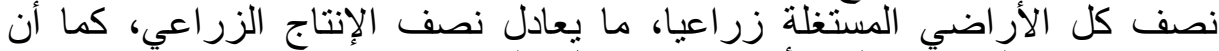

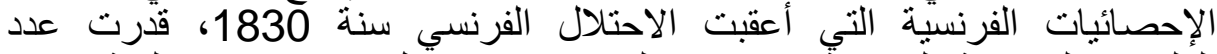

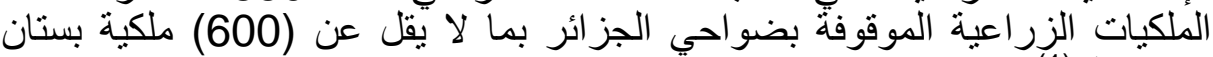

ومزر عة. (1) ملزيات 


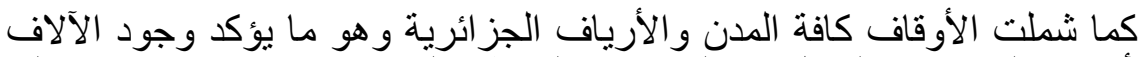

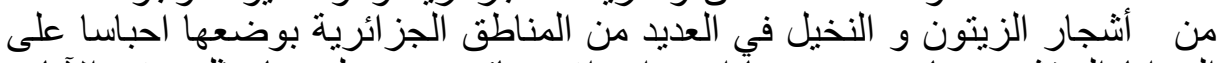

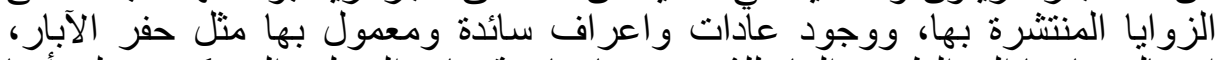

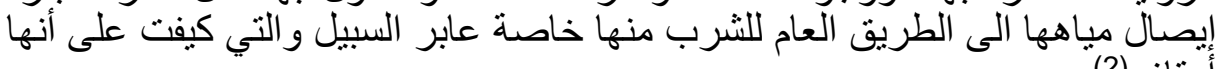

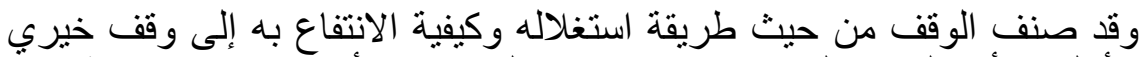

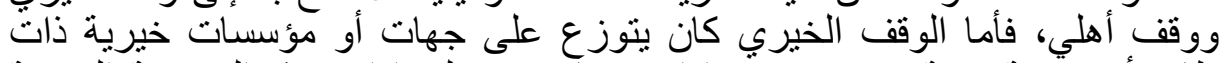

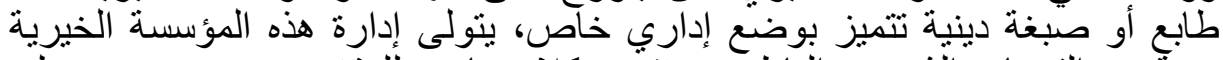

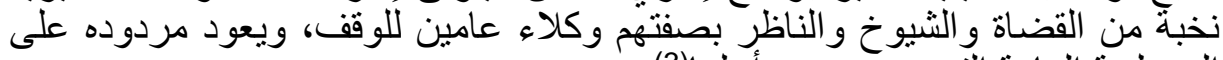
المصلحة العامة التي حبست من أجلهاة النيان.

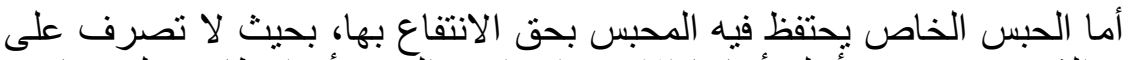

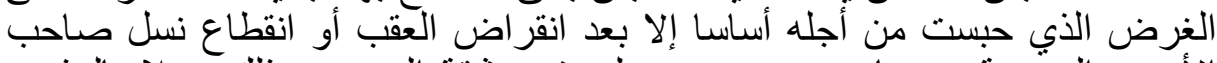

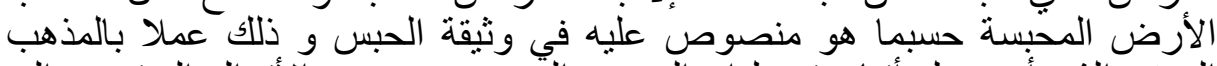

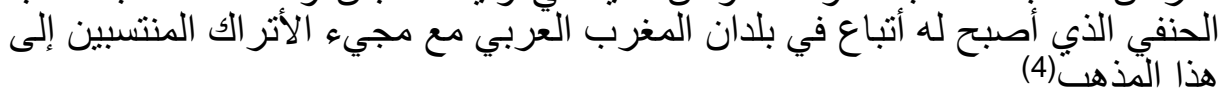

وقد بلغت الأوقاف في الفترة العثمانية شأن كبير وتطورت تطور ملحوظ، تميز

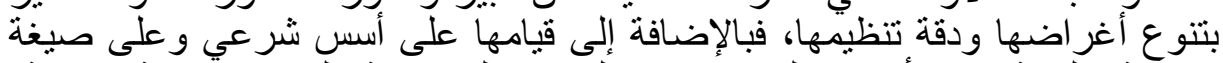

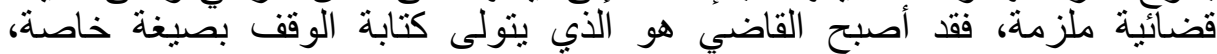

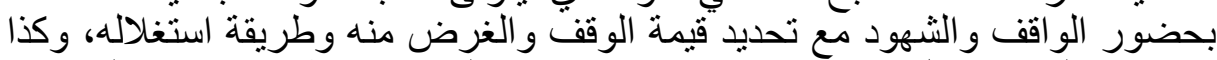

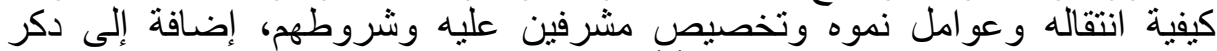
تاريخ الوقف وتوقيع القاضي و الثهود" (5).

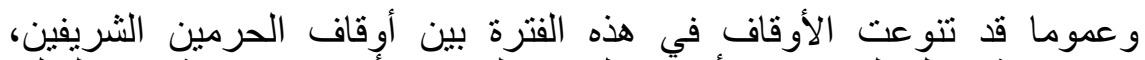

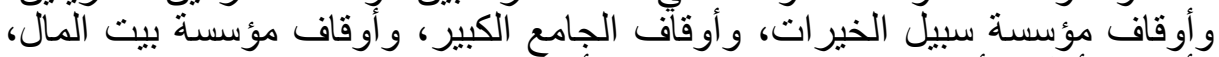

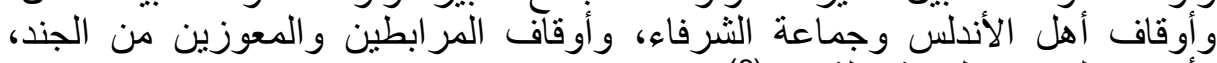
وأوقاف المر افق العامة و التكنات(6).

\section{الفرع الثاني: وضعية الأوقاف في الفترة الاستعمارية:}

إن الوقف يشكل أحد العوائق التي حالت دون تطور التوسع الاستعماري بشكل

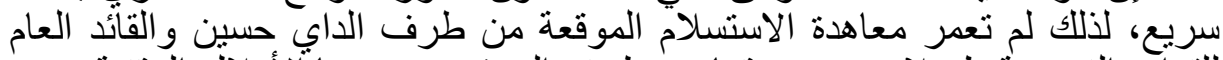

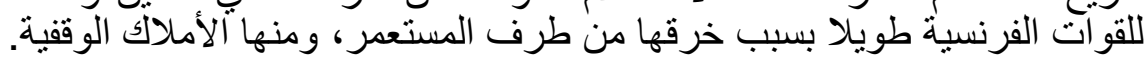

فقد قامت السلطات الاستعمارية كخطوة أولية بإصدار قرار بتاريخ 08 سبتمبر الإبر

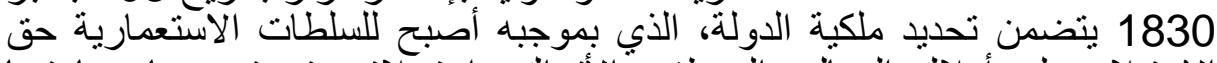

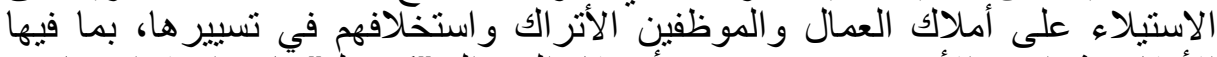

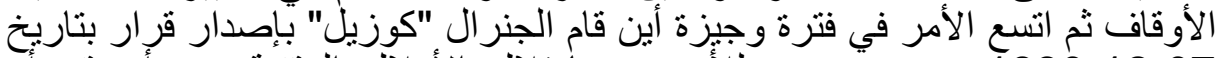

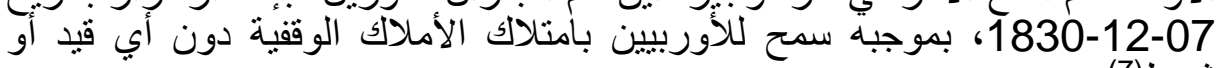

ثم وضعت هذه الأملاك كلها تحت مراقبة الحكومة الفرنسية بموجب القبر القرار

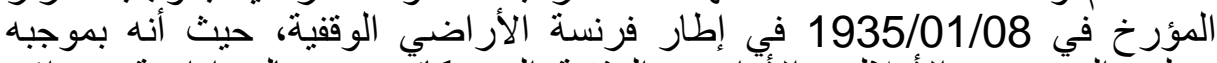

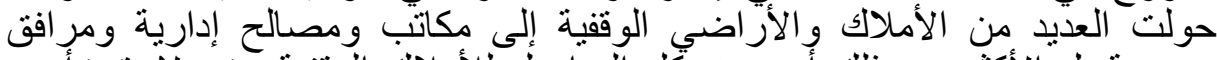

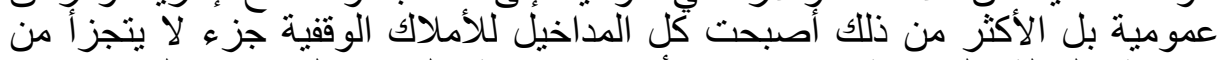

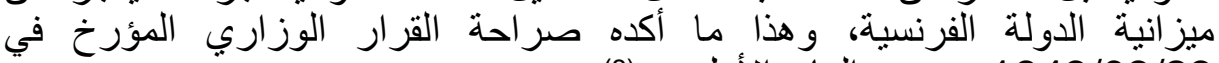
1843/03/23 بموجب المادة الأول منه(8). 
ليتأكد بعد ذلك السياسة الاستعمارية للمستعمر بسنه أول قانون يرمي إلى إلى تتظيم

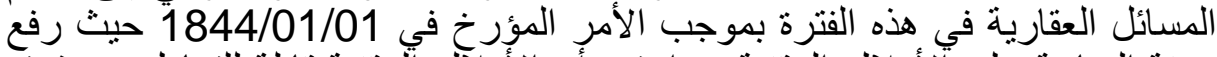

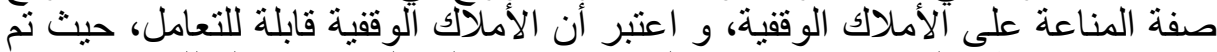

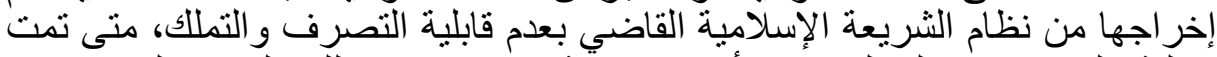

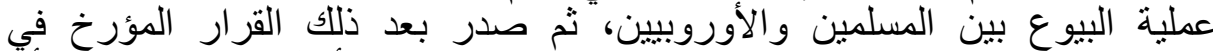

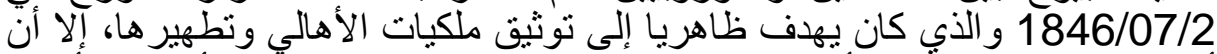

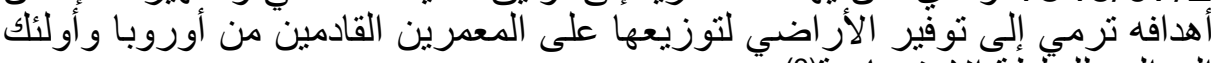

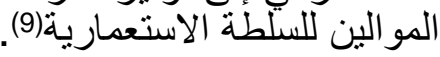

ليصدر القانون المؤرخ في الفي التئس الذي سعى إلى تتظيم وحماية

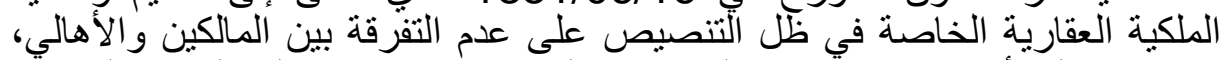

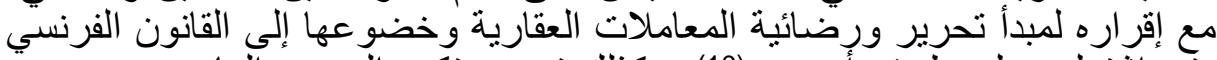

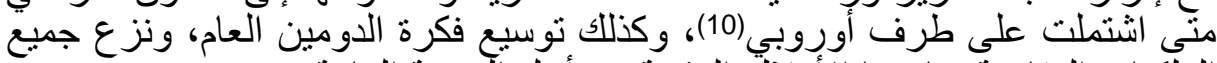
الملكيات العقارية بما فيها الأملاكت الوقفية من أجل الّمنفعة العامة.

غير أنه بصدور القرار 1858/10/30 أخضع الوقف لأحكام المعاملات

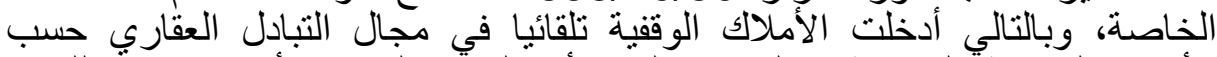

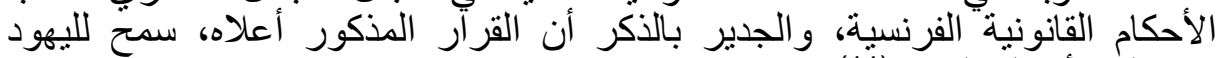

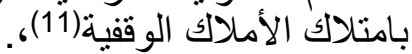

ويعد أهم قانون كان له الأثر في تصفية أملاك الأهالي بصفة عامة والأملاك

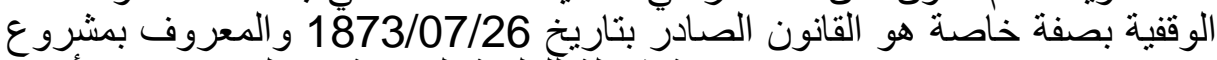

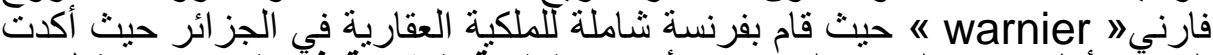

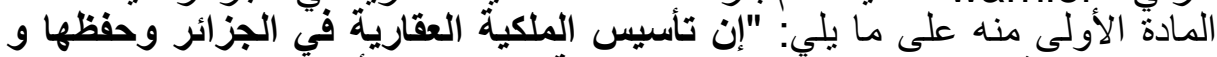

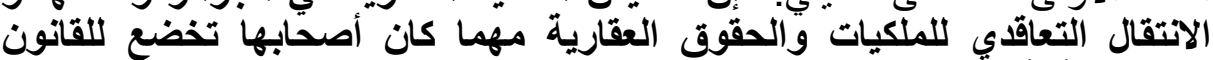

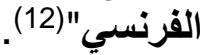

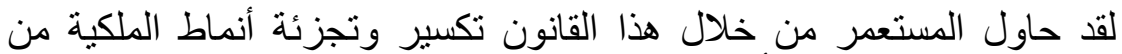

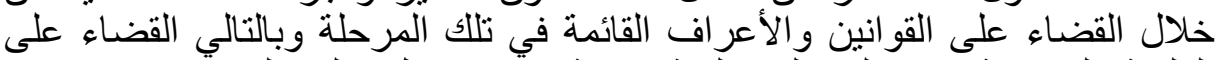

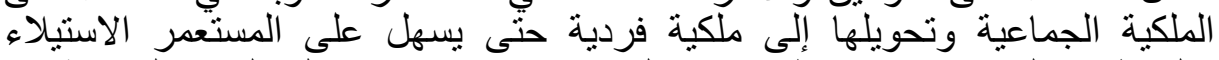

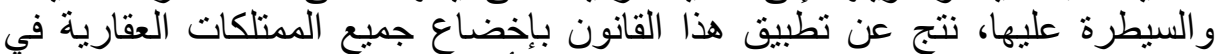

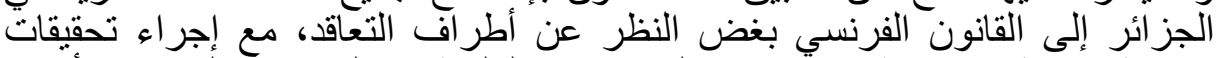

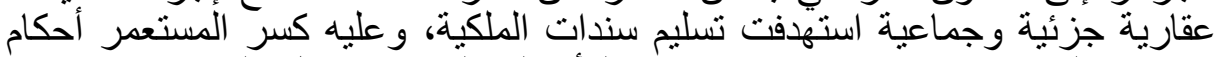

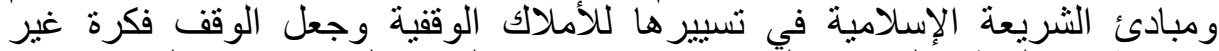

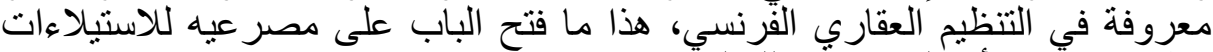
انطلاقان فكرة أن الوقف لأ ماللك له له

\section{المطلب الثانىم: وضعية الأوقاف في المرحلة الاشتراكية:}

إن غياب الحماية القانونية للأوقاف في هذه المرحلة زادت فرصة الاعتداء

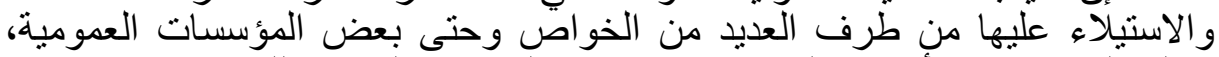

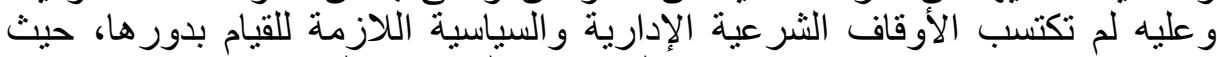

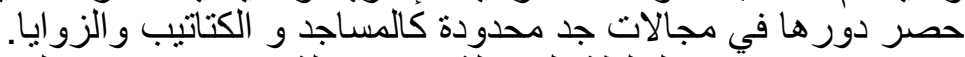

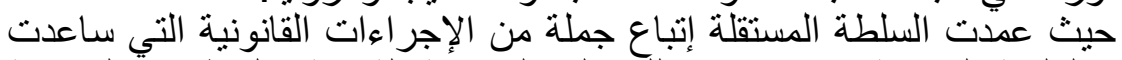

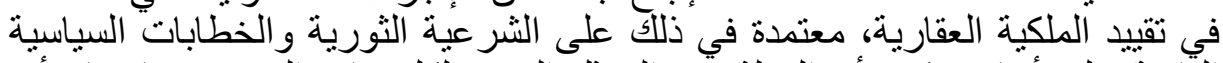

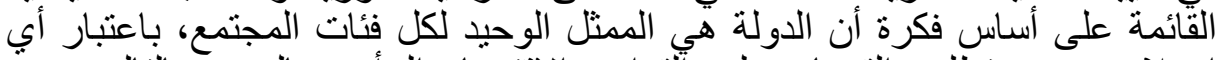

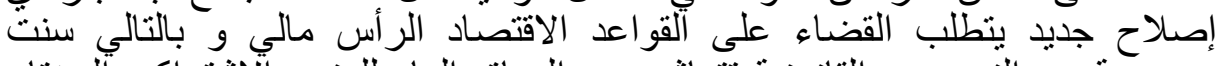

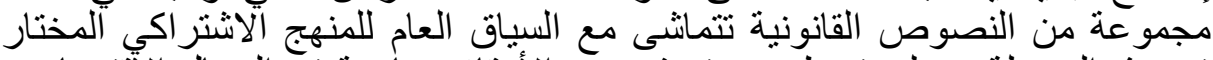

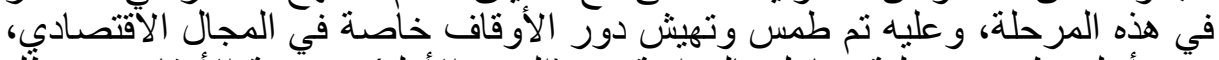
ومن أجل نظرة تفصيلية نتناول بالدراسة في (الفرع الأول) وضعية الأوقاف في ظُّل 
المرسوم رقم 283/64، بينما تناولنا بالدر اسة في (الفرع الثاني) وضعية الأوقاف في

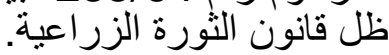

\section{الفرع الأول: وضعية الأوقاف فح ظل المرسومرقم 283/64 :}

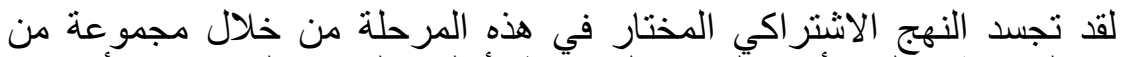

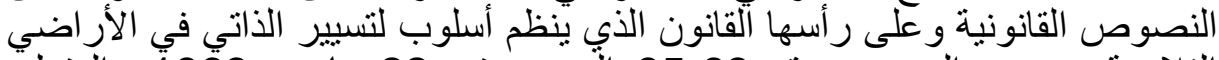

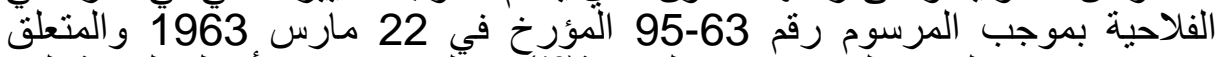

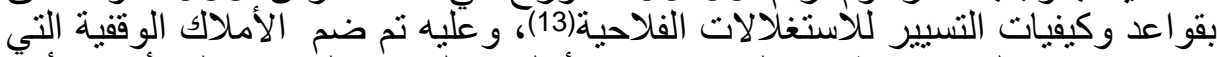

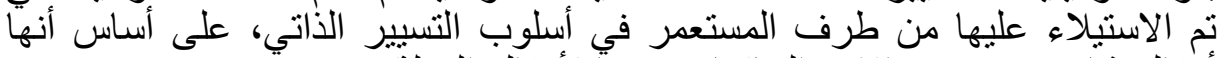

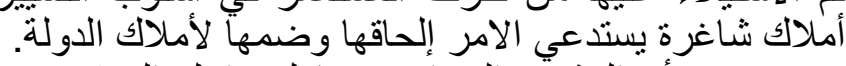

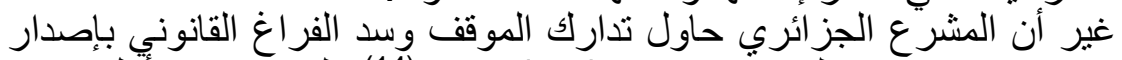

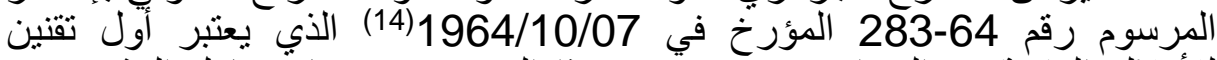

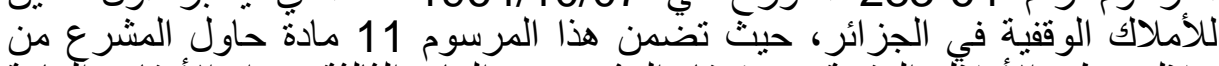

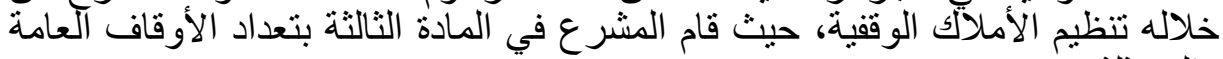

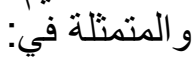
- - الأملاك التي تؤدى فيها شعائر الدين.

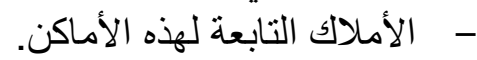

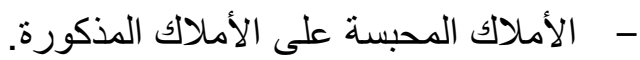

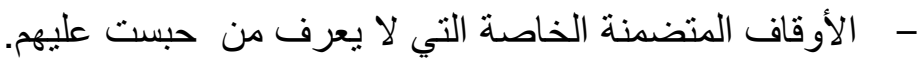
- الأوقاف التي ضمت إلى أملاك الدولة و التي لم يجري تفويتها أو تخصيصها.

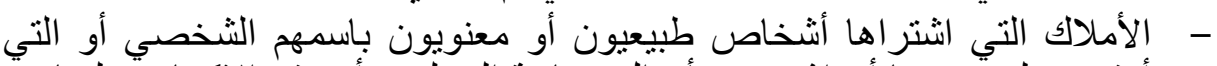

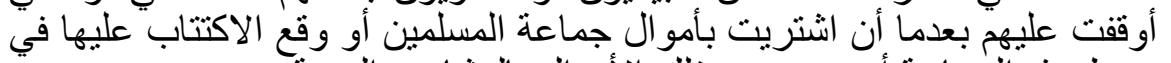

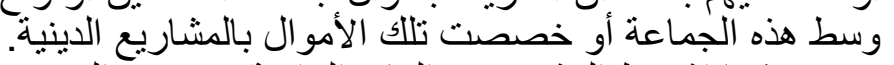

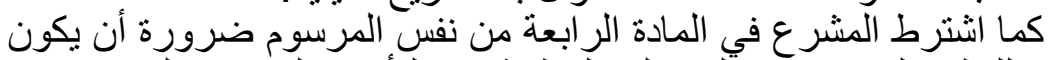

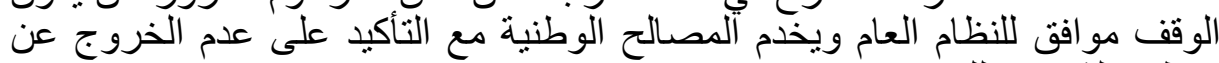

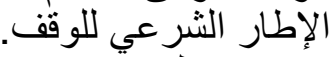

و عليه منح هذا المرسوم صلاحيات واسعة لوزير الأوقاف فيما يخص تسيير

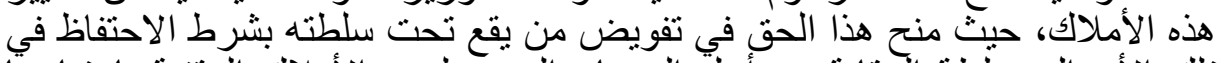

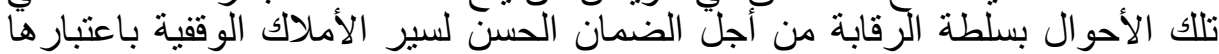

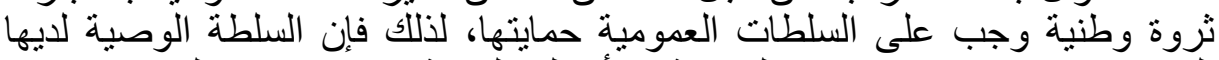

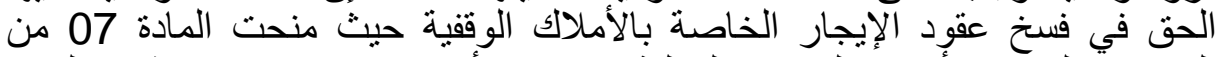

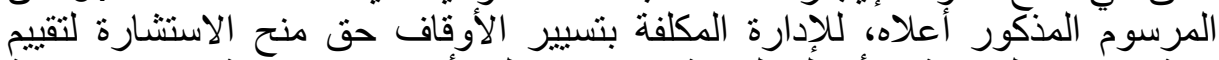

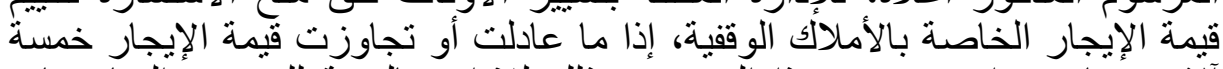

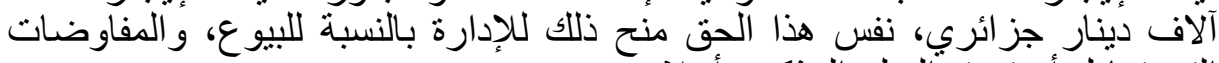
التي تعادل أو تفوق ألمبلغ المذكور أعلاه.

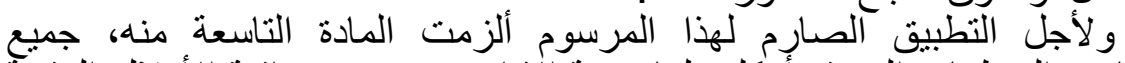

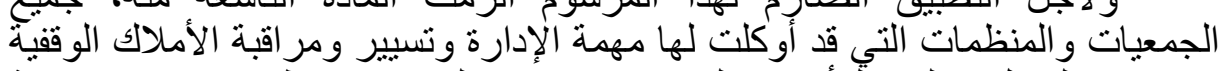

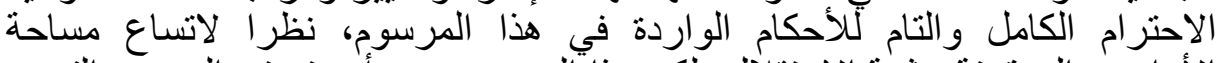

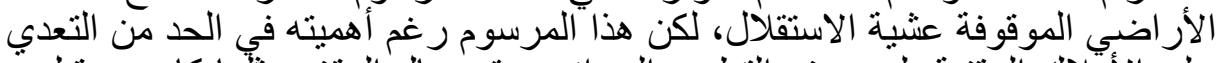

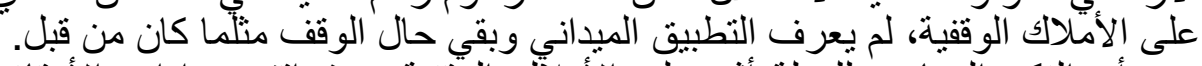

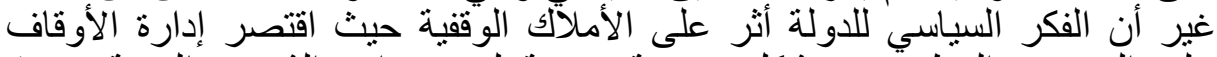

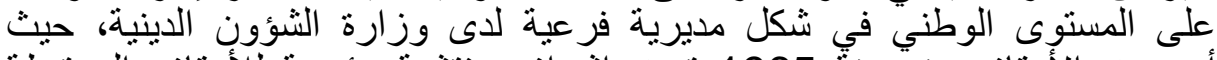

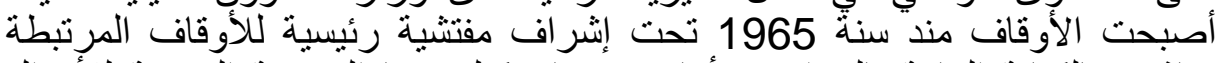

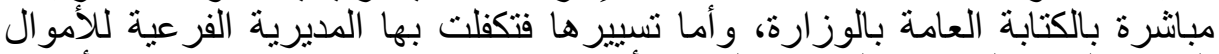

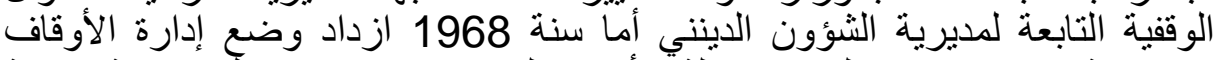

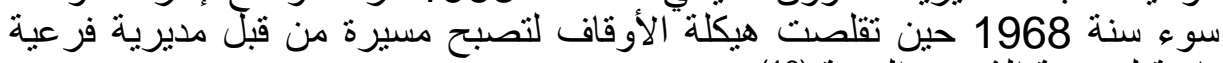
تابعة لمديرية الثؤون الدينية. و عليه تم الاعتداء وتهميش الأملاك الوقفية بطريقة مقننة تظهر جليا من خلال 
قانون الثثررة الزراعية أين أكد المشرع على تبعية العديد من الملاك الوقفية للصندوق

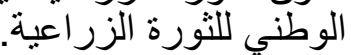

الفرع الثاني: وضعية الاوقاف في ظل قانون الثورة الزراعية

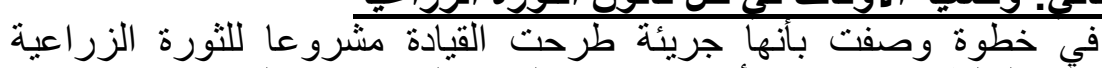

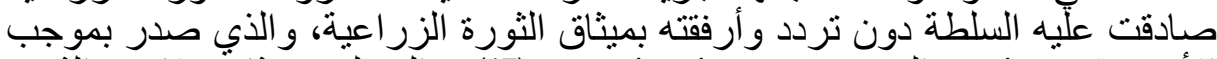

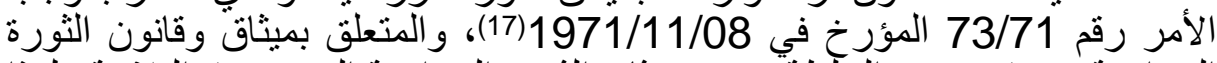

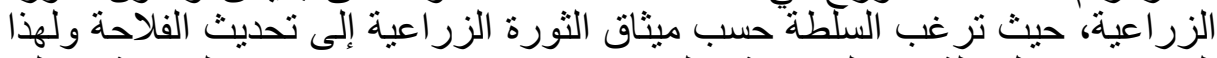

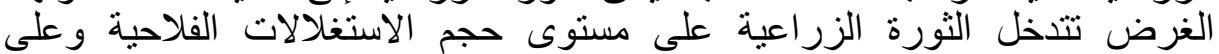

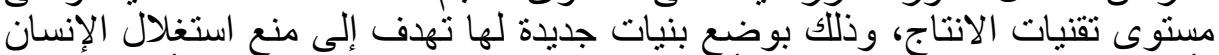

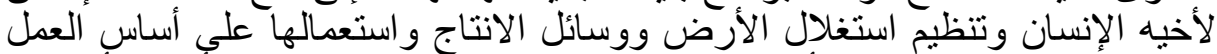

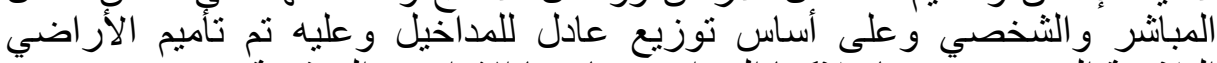

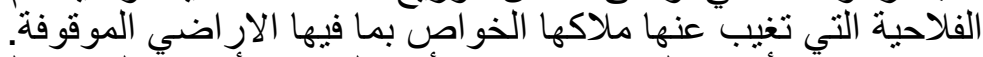

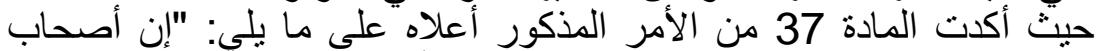

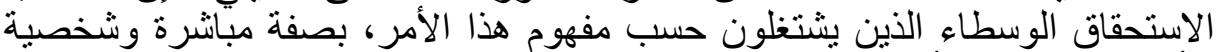

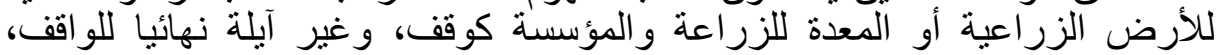

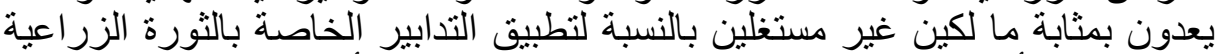

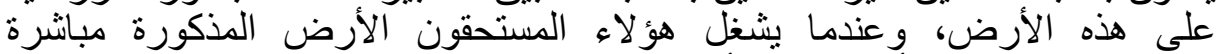

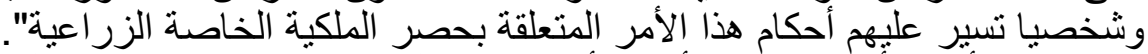

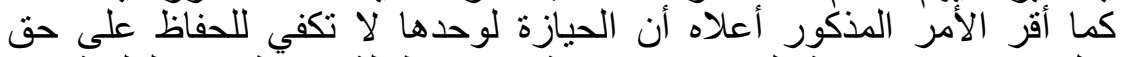

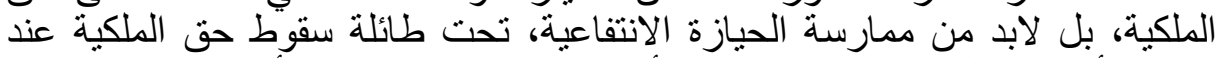

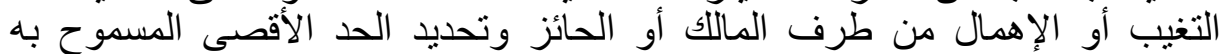

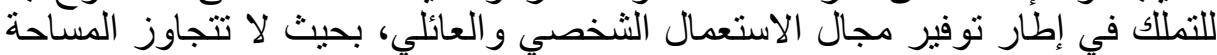

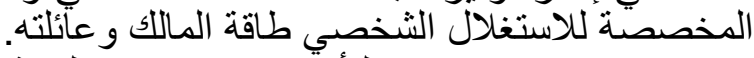

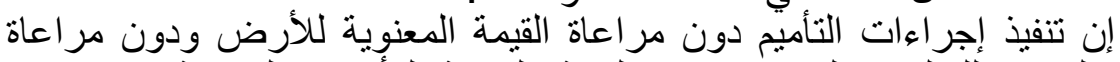

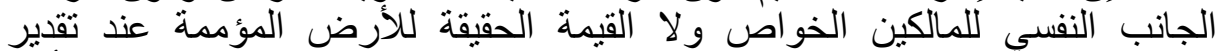

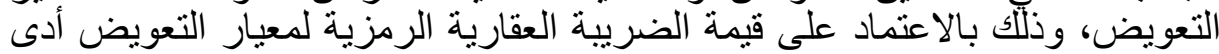

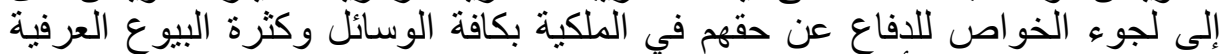

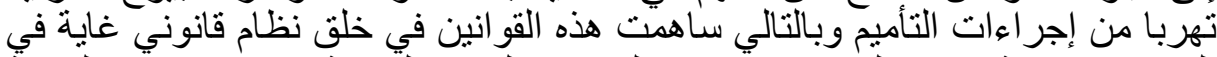

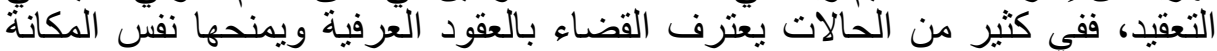

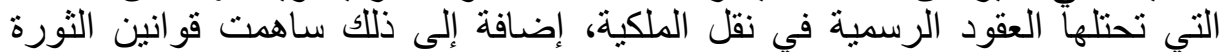

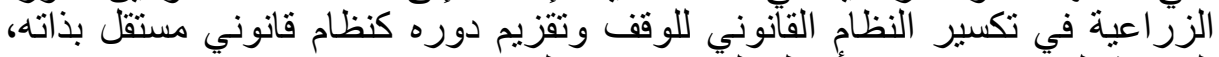

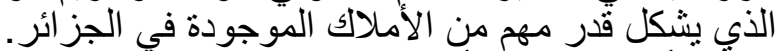

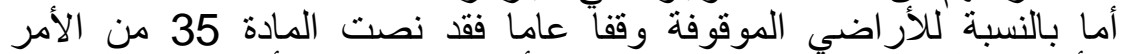

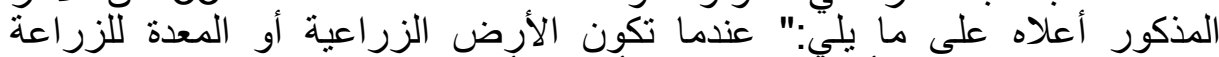

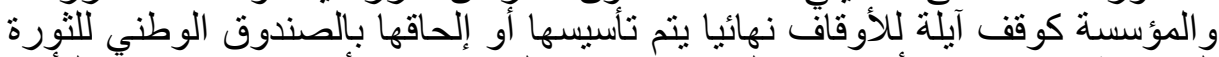

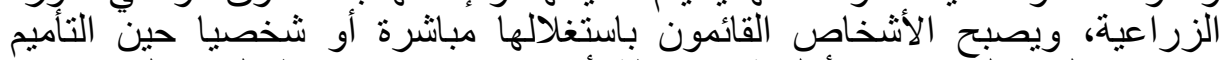

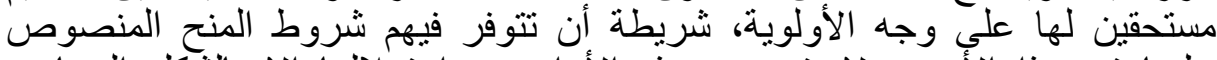

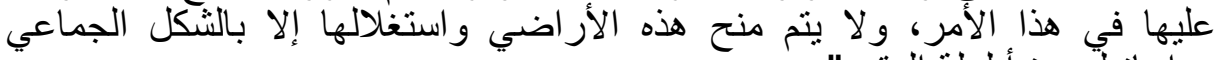

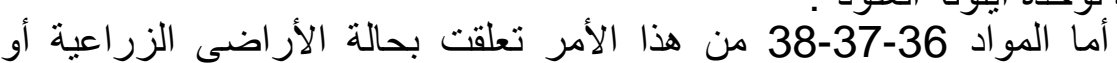

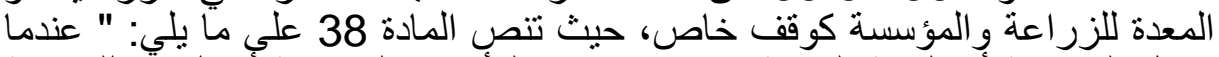

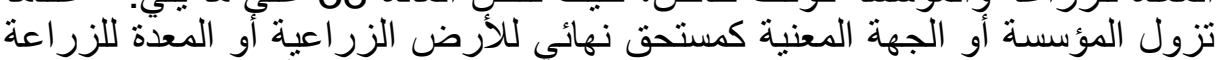

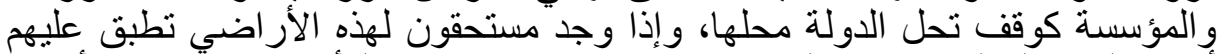

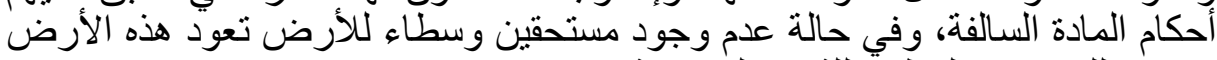

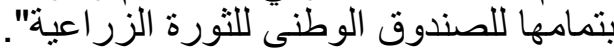

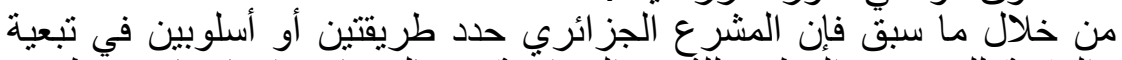

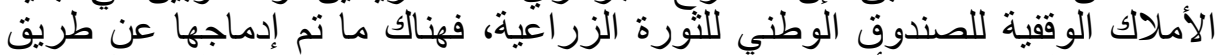

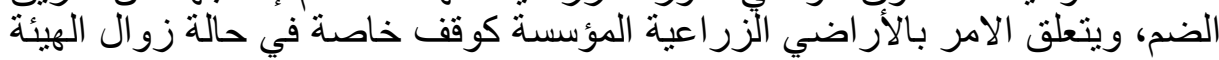


أو الجهة المستفيدة من ذلك الوقف، حيث تحل الدولة محل هذه الهيئة أما النوع الثاني

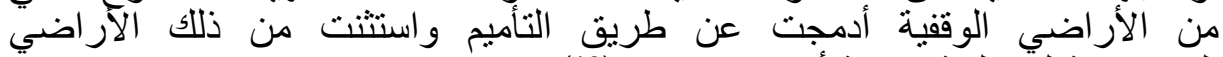

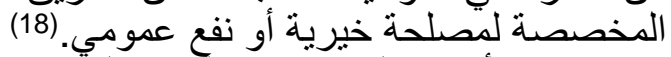

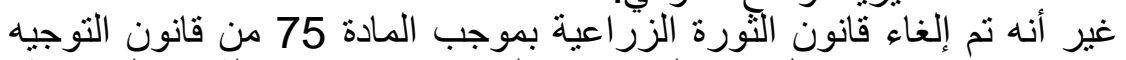

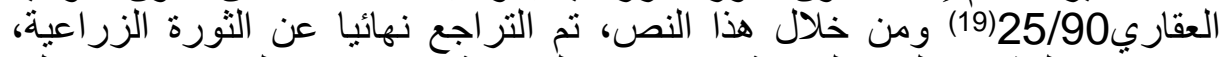

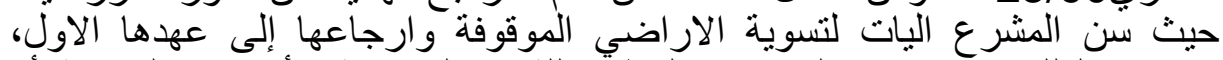

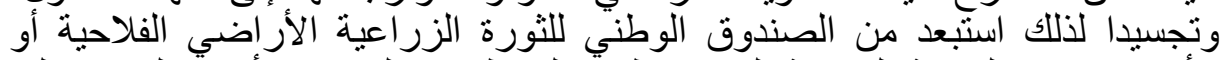

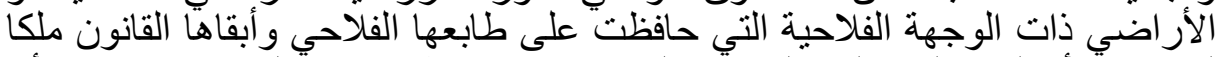

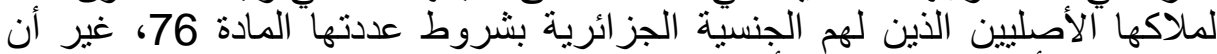

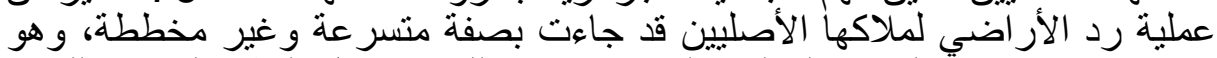

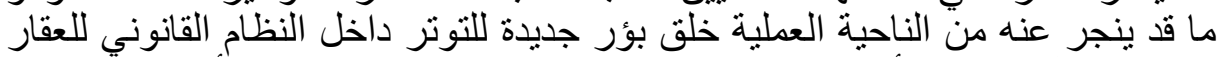

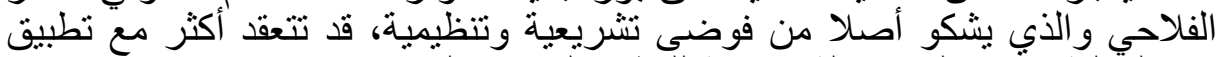

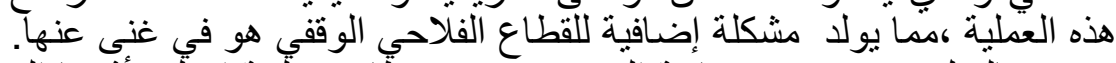

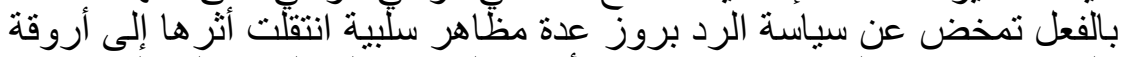

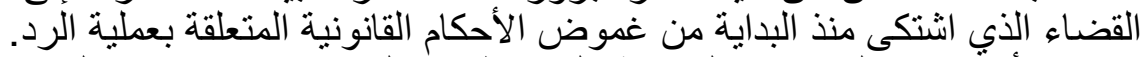

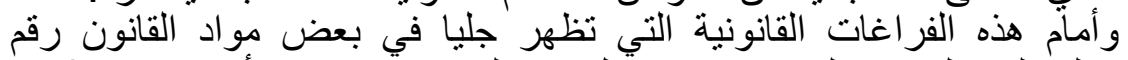

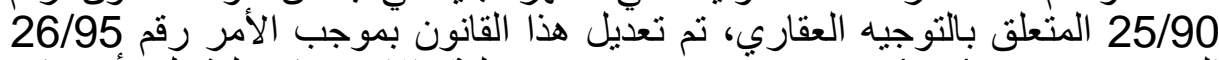

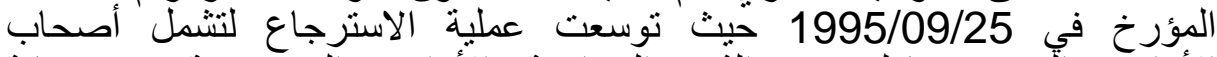

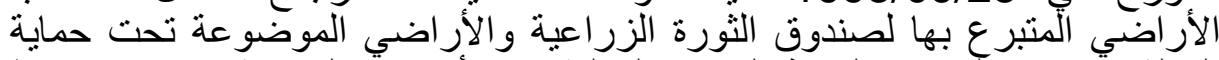

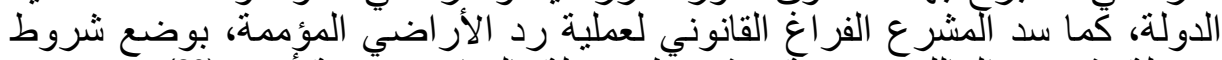

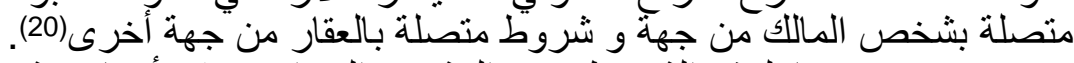

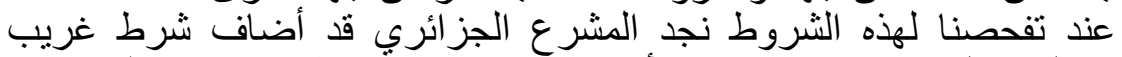

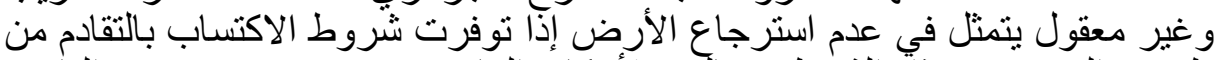

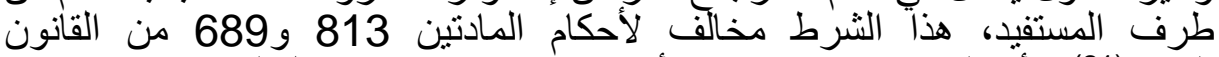

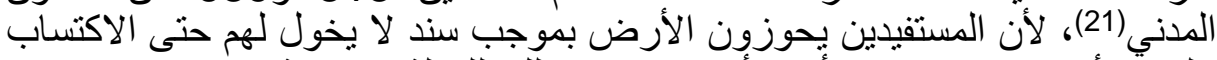

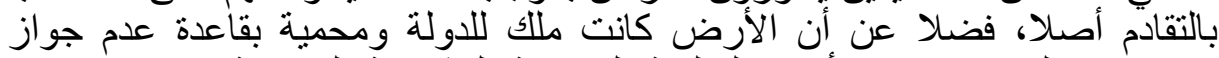

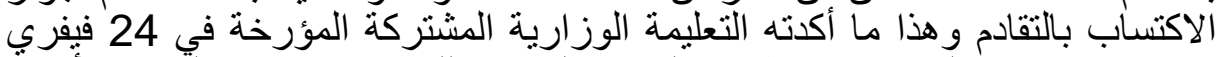

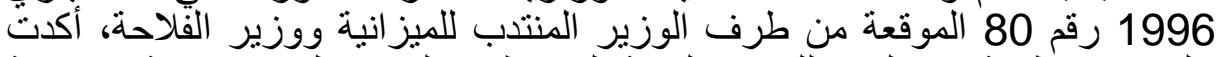

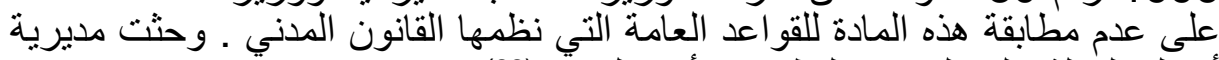

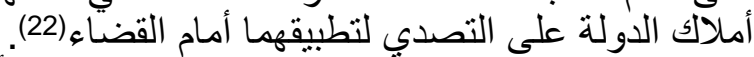

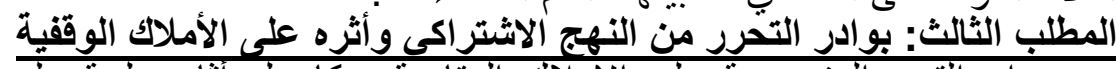

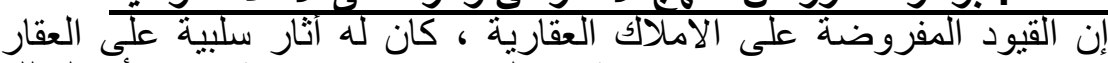

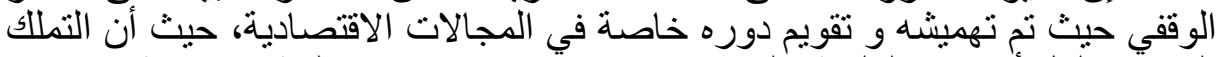

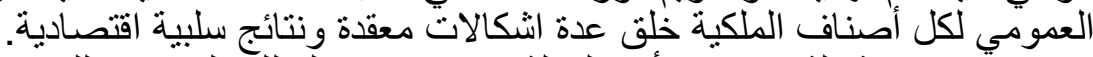

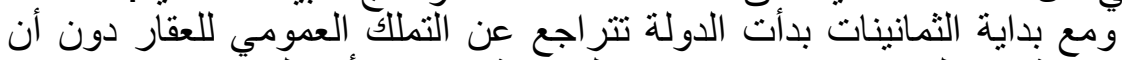

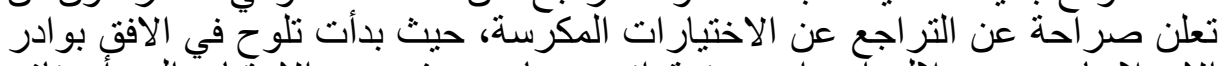

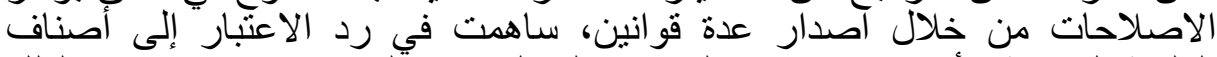

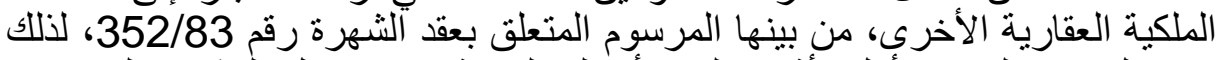

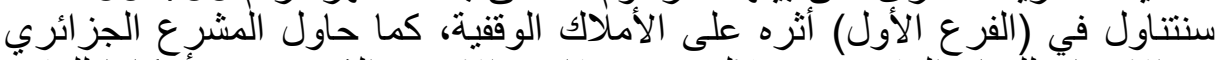

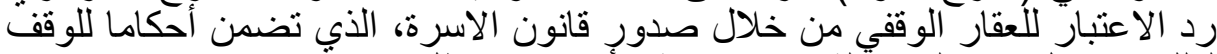

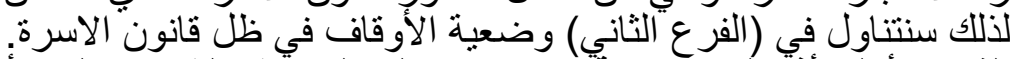

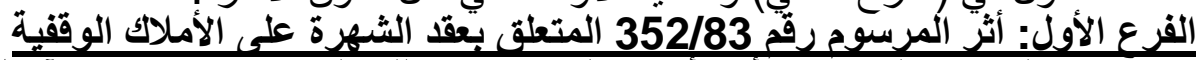

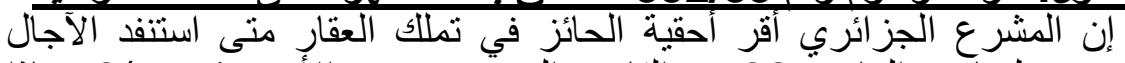

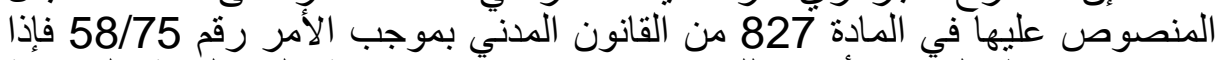

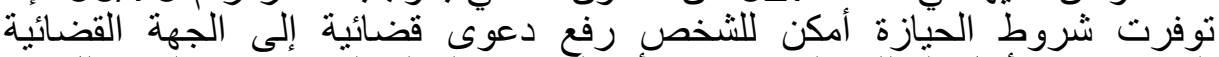

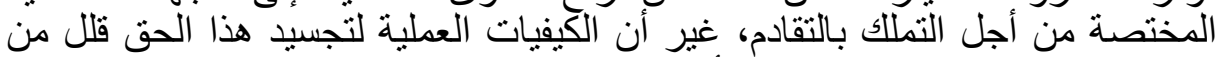

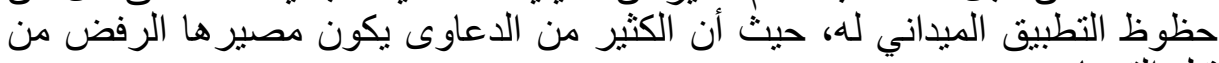

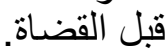

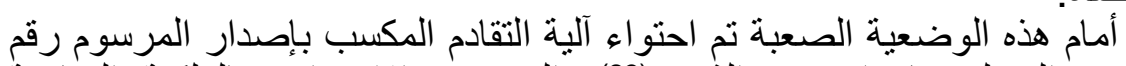

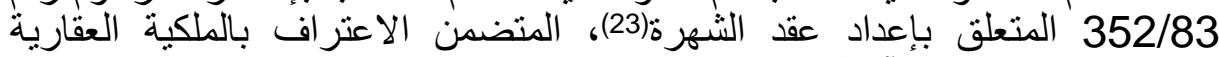
بإجر اءات بسيطة وفي آجال قصيرة، حيث تم تطبيقه ميدانيا لمرحلة طويلة امتدت إلى بلى 
سنة 200724) - (24).

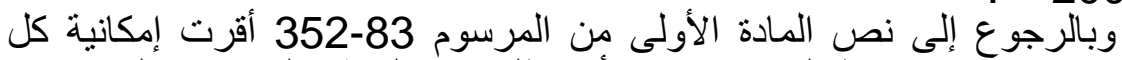

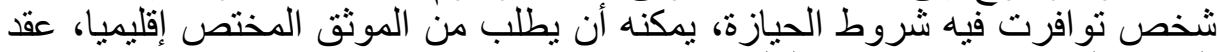

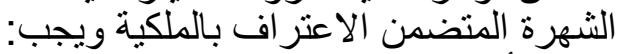

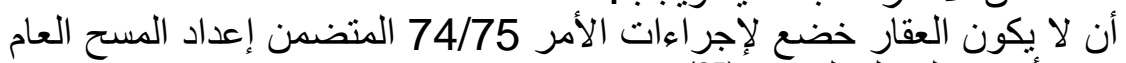

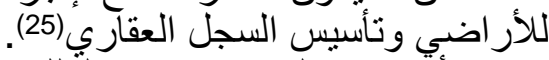

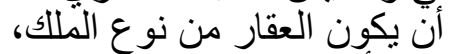

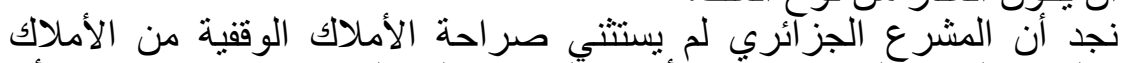

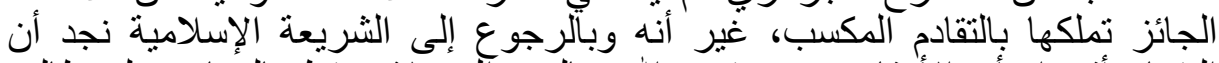

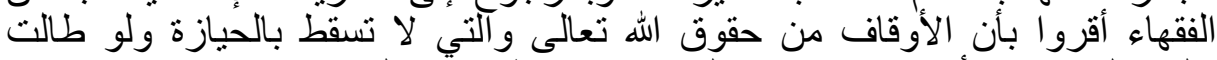

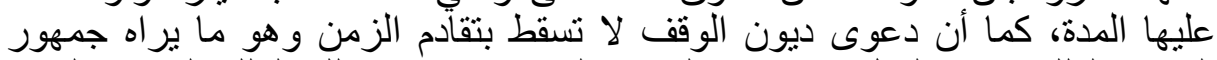

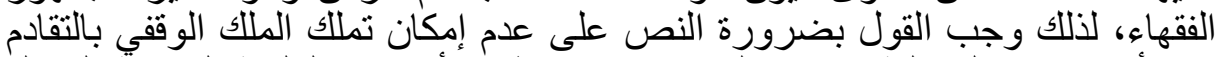

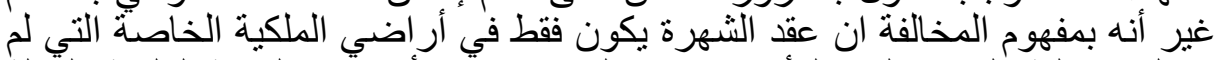

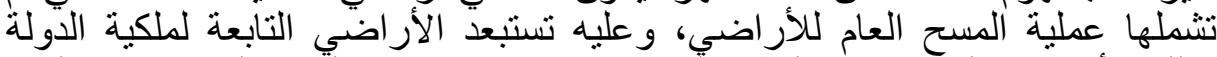

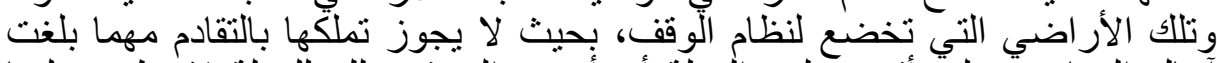

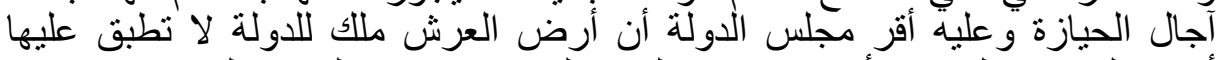

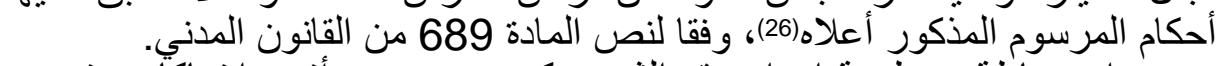

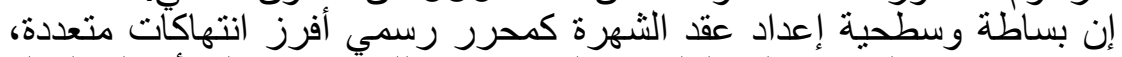

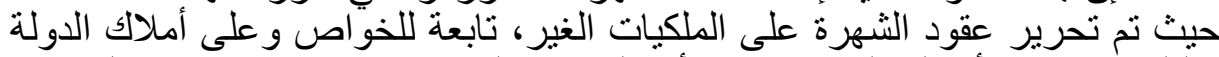

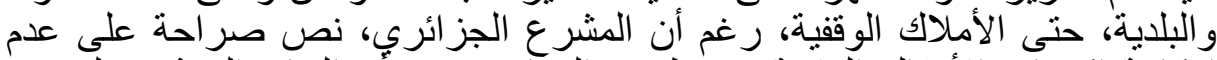

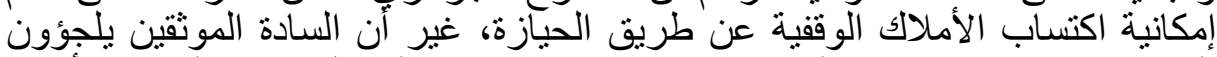

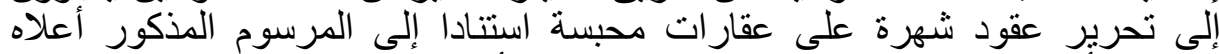

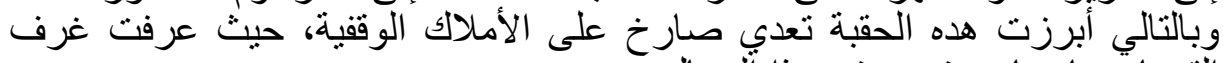

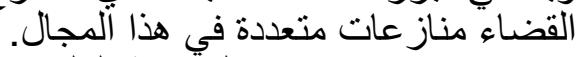

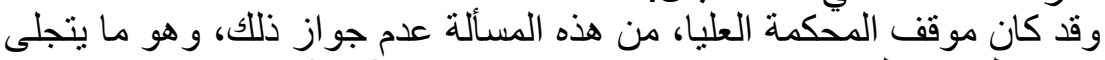

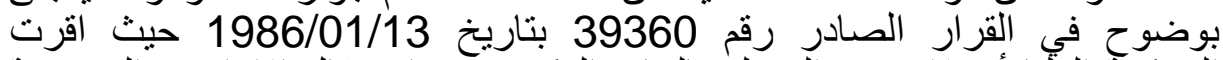

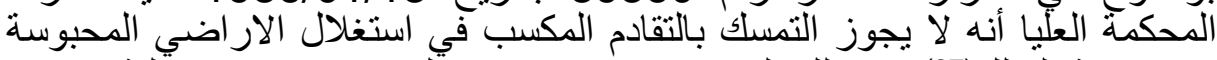

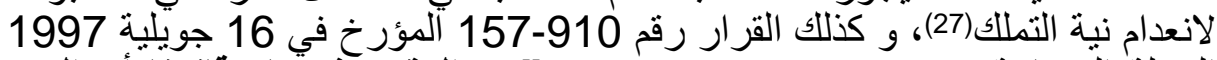

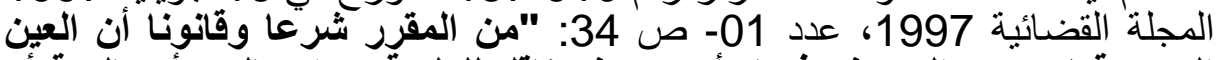

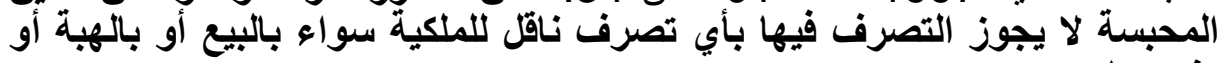

و'عليه فإن الحكم الصادر من محكمة الارجة الأولى ببوسعادة القاضي بإبطال بغير هما.

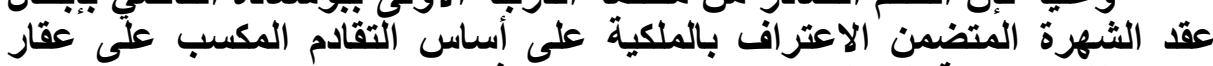

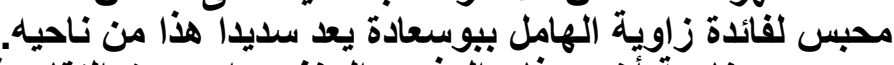

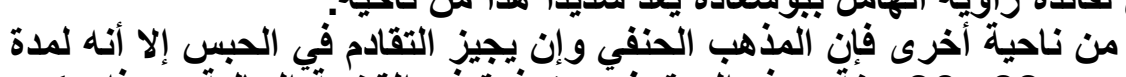

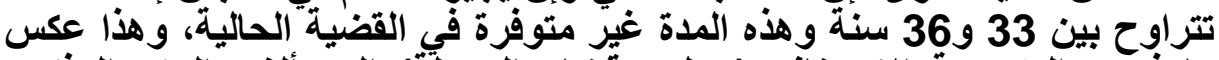

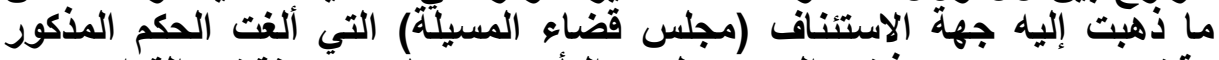

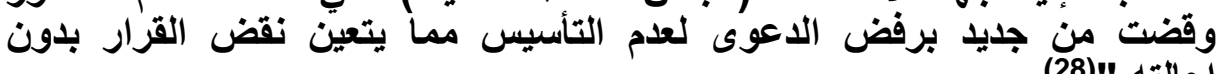
(28)" إحالته.

ألفرع الثاني: وضعية الأملاك الوقفية في ظل صدور قانوانون الأسرة:

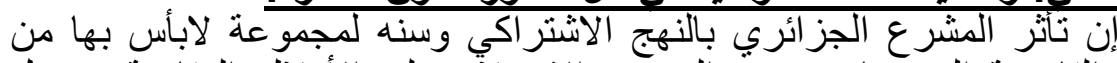

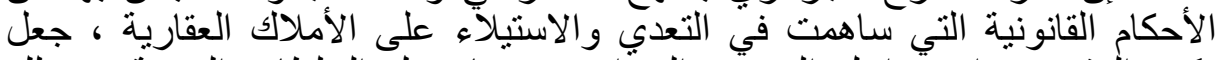

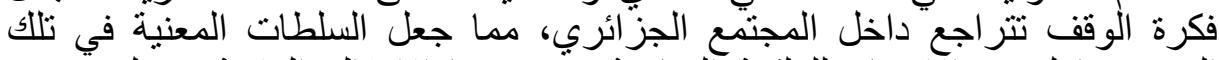

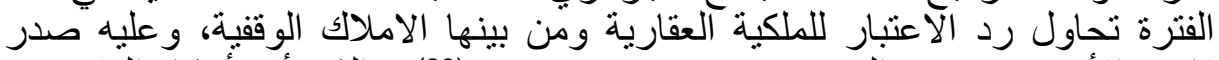

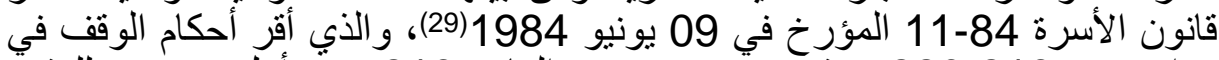

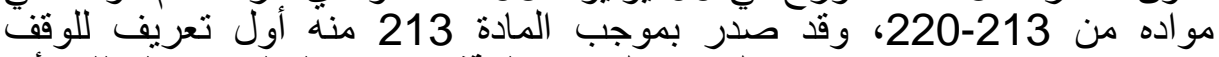

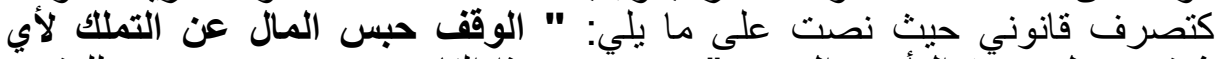

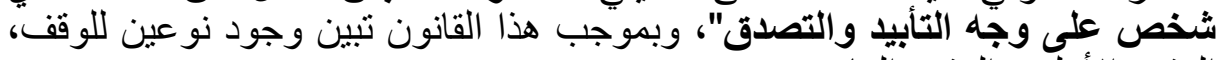
الوقف الأهلي و الوقف التعائ. 
ما يلاحظ على هذه المواد من قانون الأسرة أنها نصت فقط على القوام القو اعد العامة

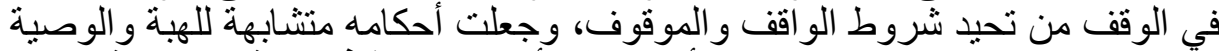

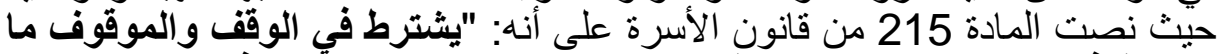

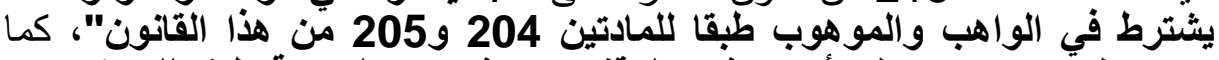

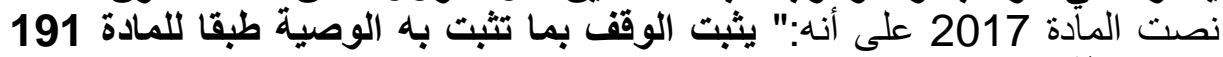

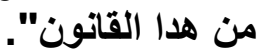

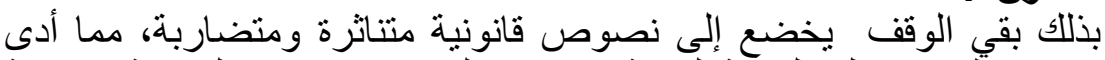

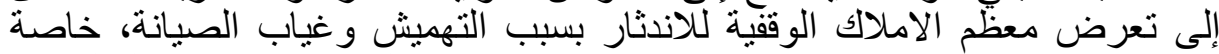

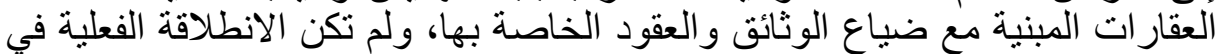

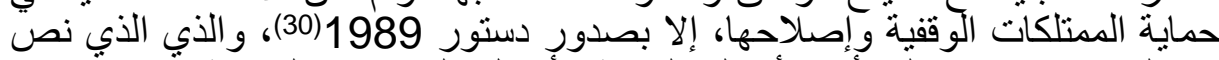

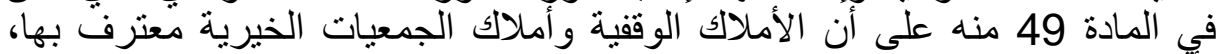

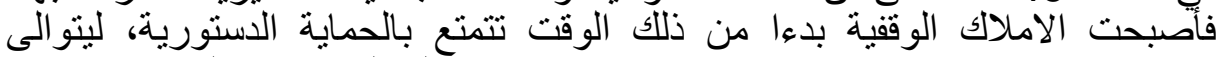

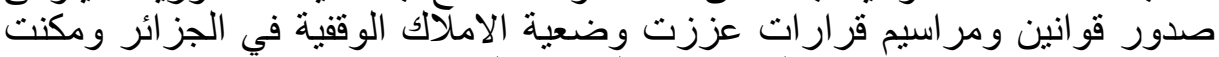

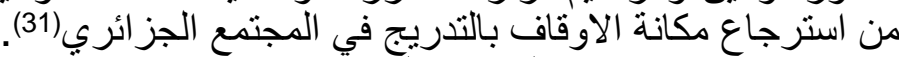

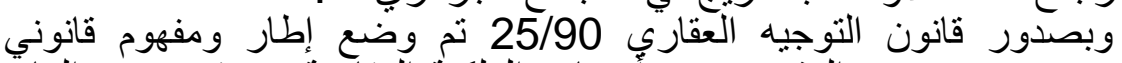

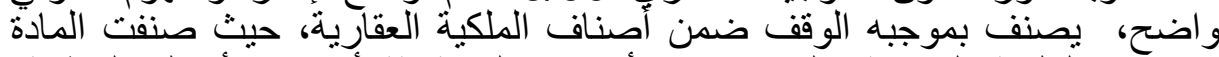

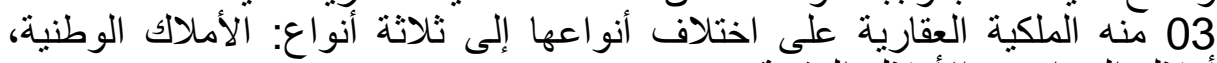
أملاك الخواص و الأملاكك الوقنية.

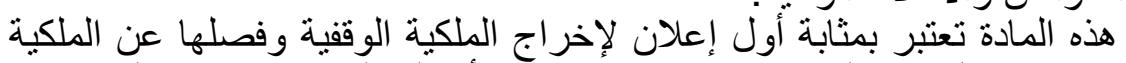

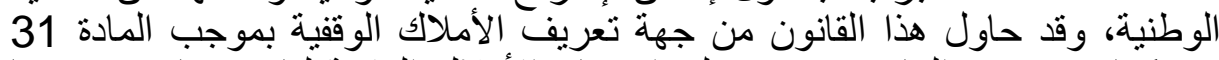

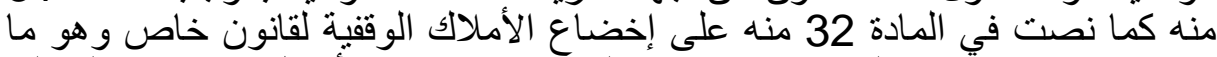

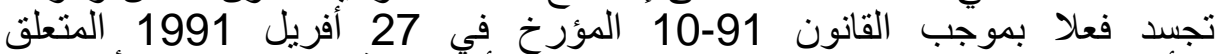

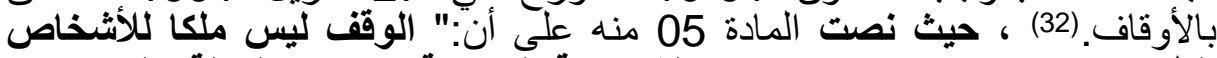

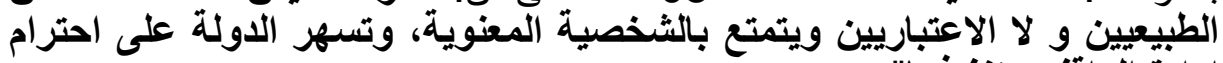
إرادة الواقف وتنفيذها".

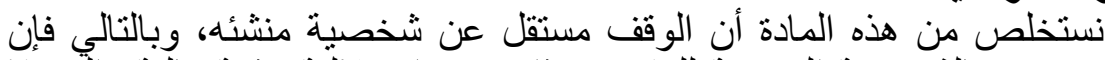

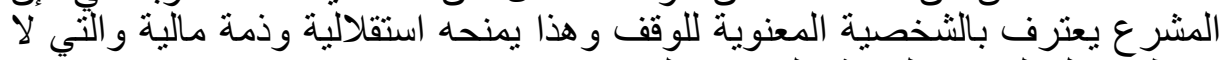

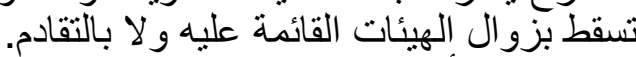

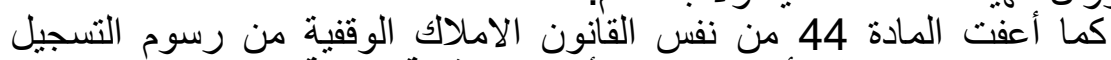

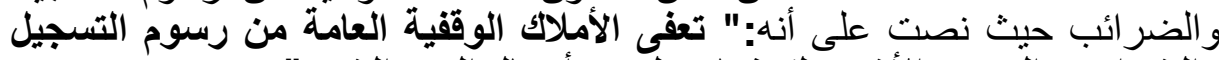

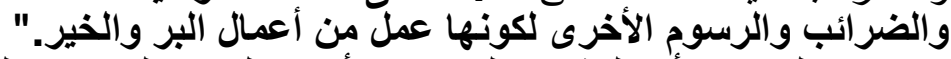

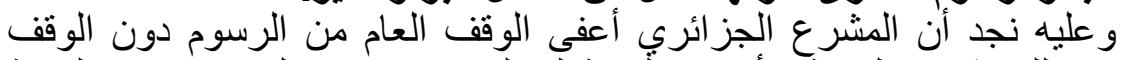

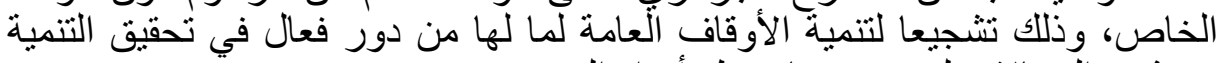

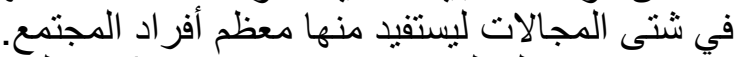

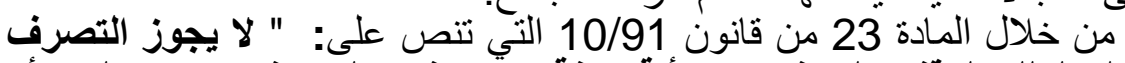

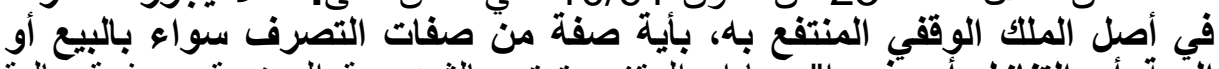

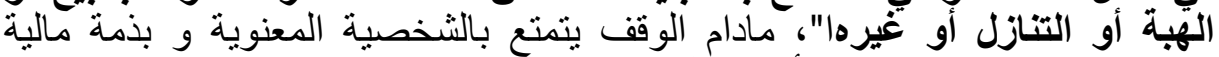

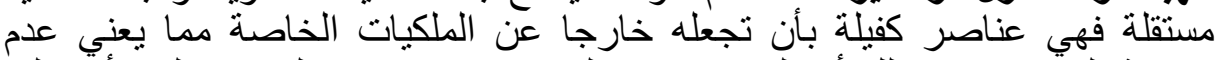

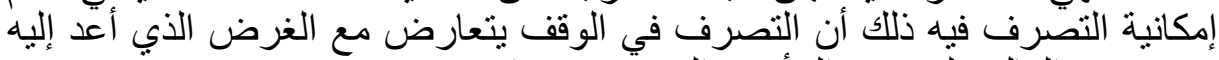

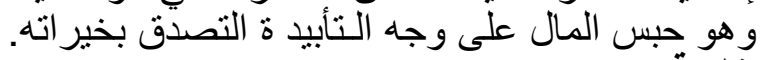

خاثمة و

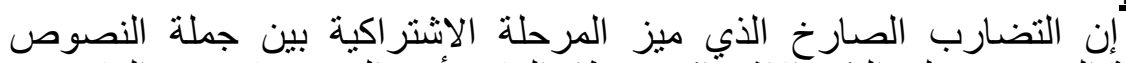

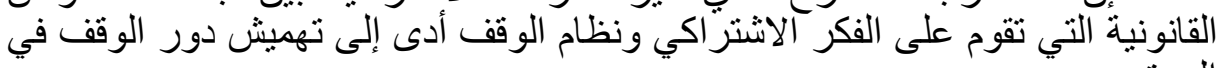

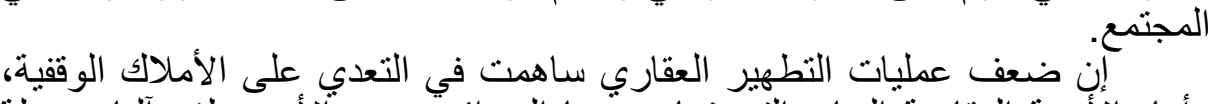

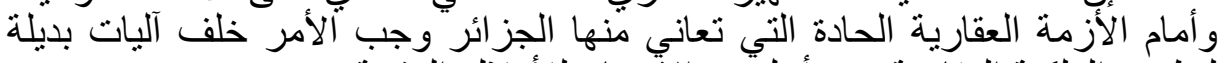

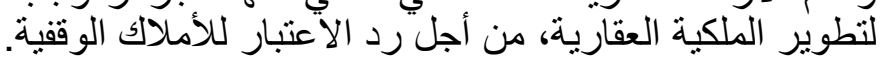

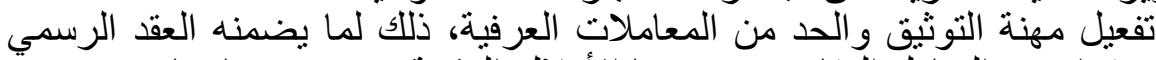

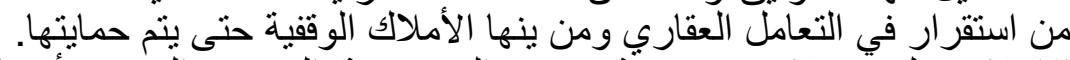

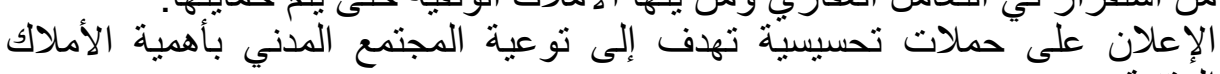
الوقفية 


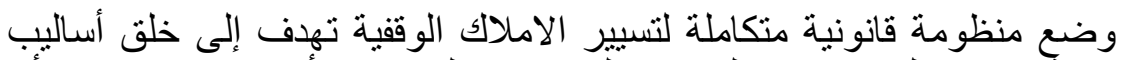

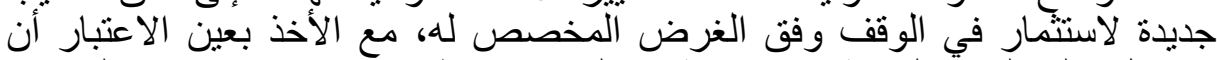

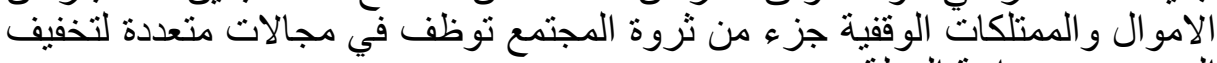

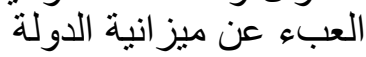

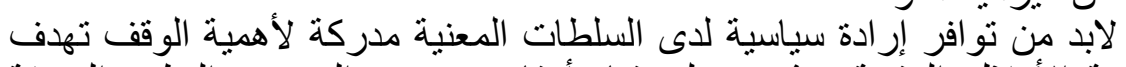

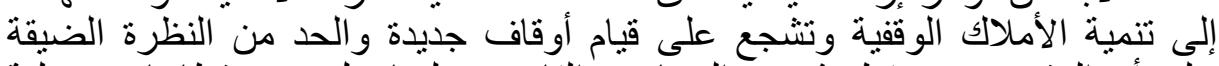

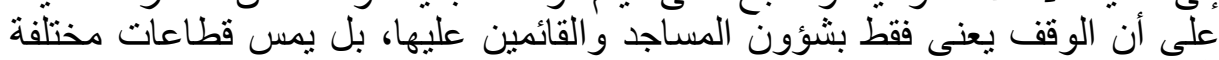

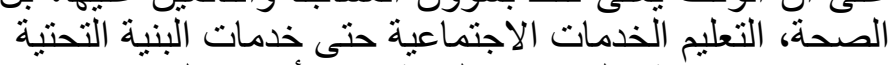

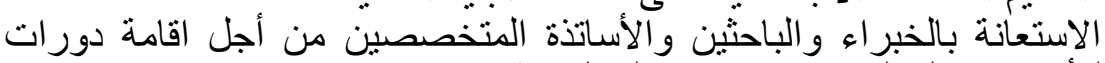

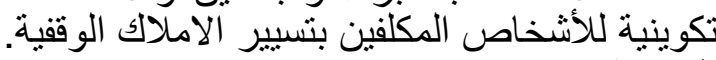

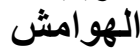

(1)-حمدي باثـا عمر، نقل الملكية العقارية، دار هومة للطباعة والنشر والتوزيع،

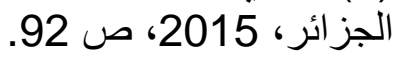

(2)-ناصر سعيدوني، دراسات في في الملكية العقارية، المؤسسة الوطنية للكتاب، الجزائر

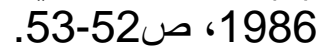

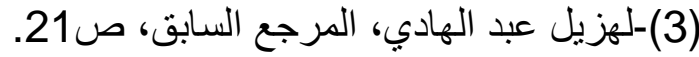

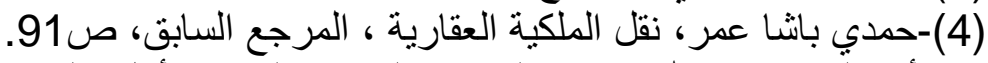
(5)-أبو القاسم سعد الله، تاريخ الجزائر الثقافي، الجزء الجغ الأول، الثركة الثركة الوطنية للنشر

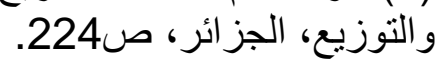

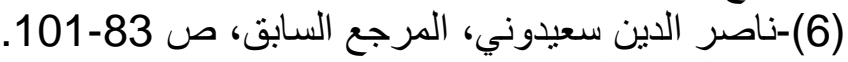

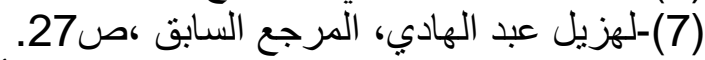

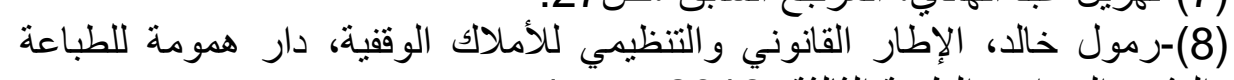

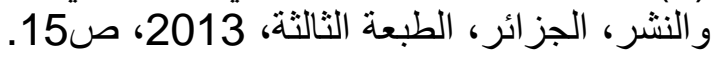

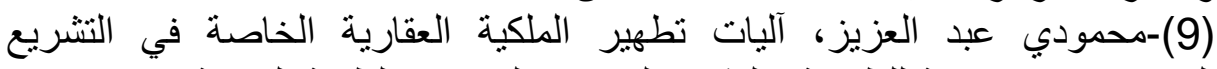

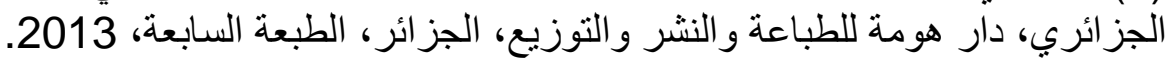

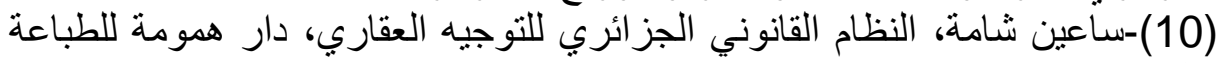

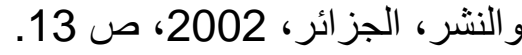

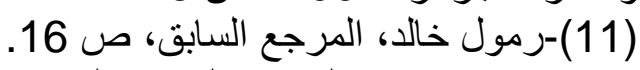

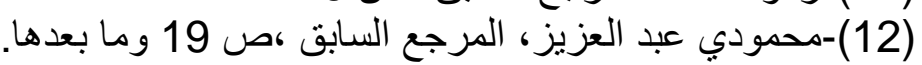

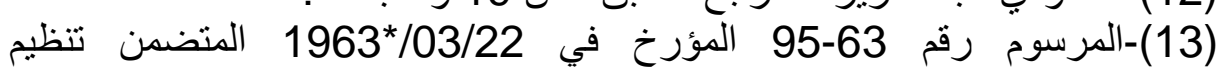

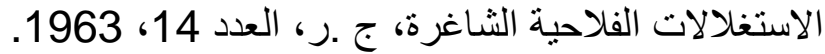

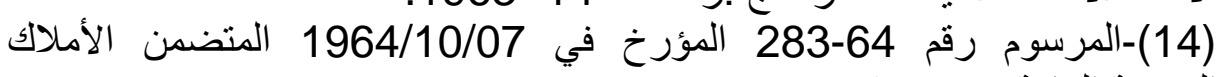

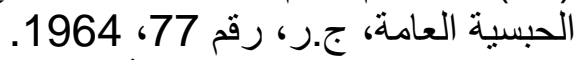

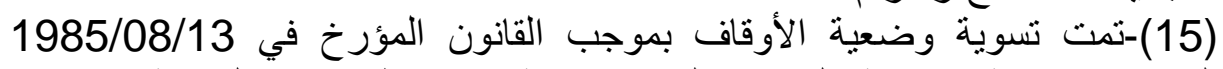

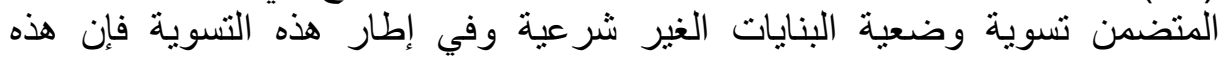

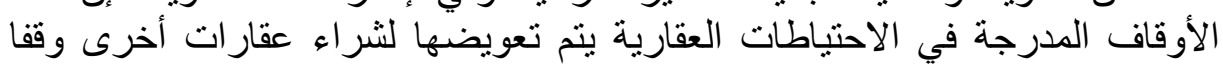

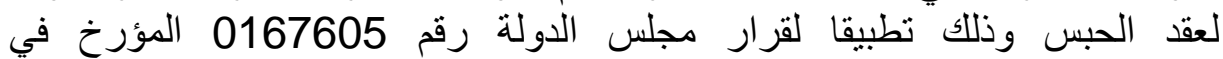

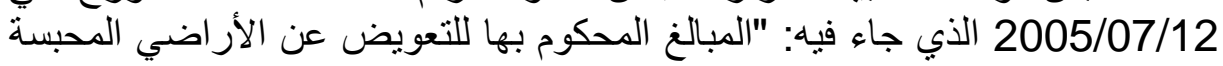

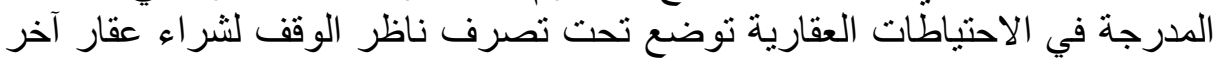

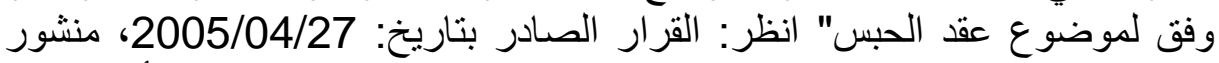

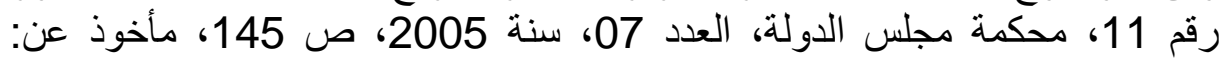

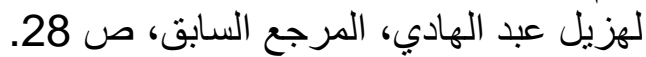

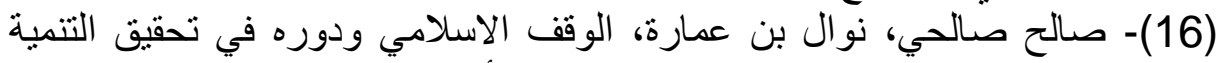

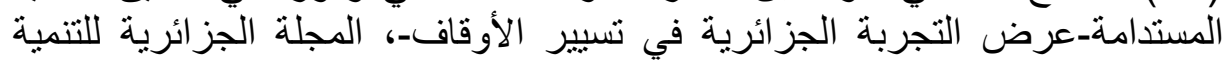
الاقتصادية، عدد01، ديسمبر 2014،صنة 161 
(17)-الأمر رقم 1971/71، المؤرخ في 1971/11/08، المتعلق بالثورة الزراعية، ج

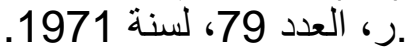

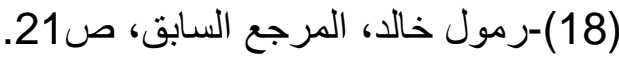

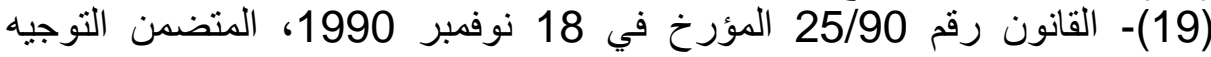

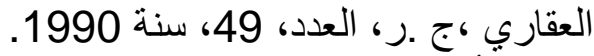

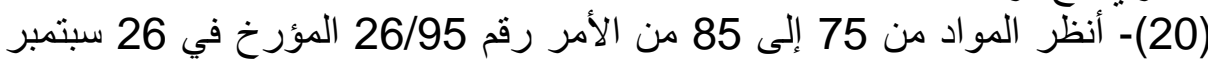

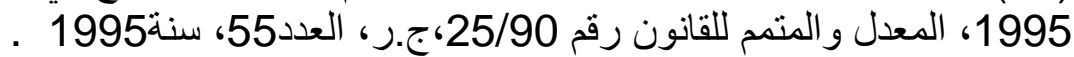

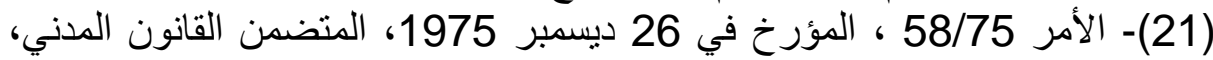

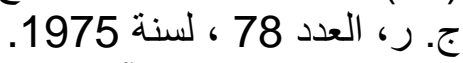
(22)- حازم عزوي، آليات تطهير الملكية العقارية الخاصة في القانون الجزائري، المرجع السابق ،ص عزمب، اليات (23)- المرسوم رقم 83-83 المابق المؤرخ في 21 ماي ،1983الذي يبين إجراءات التقادم المكسب، و إعداد عقد الثهرة.

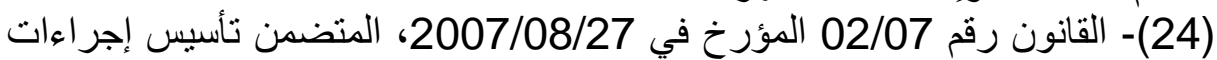
لمعاينة حق الملكية وتسليم سندات الملكية عن طريق تحقيق العيق عقاري، الجريدة الرسمية،

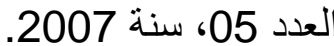

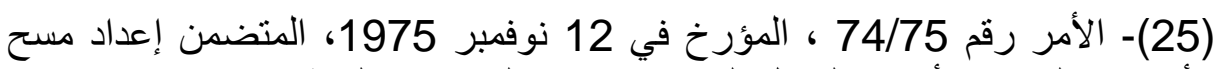

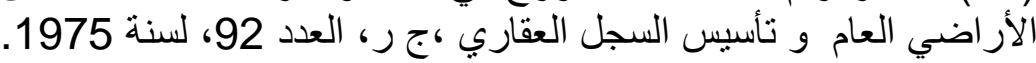
(26)- القرار رقم 5763، الصادر بتاريخ 1892/11، 2002/02/11، مجلة مجلس الدولة، العارد،

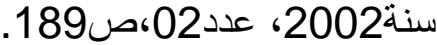

(27)-جمال سايسي، الاجتهاد الجزائري في القضاء العقاري، الجناء منشور ات كليك، الطبعة

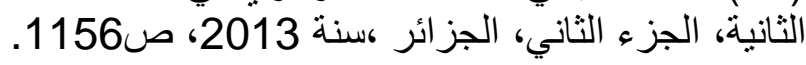

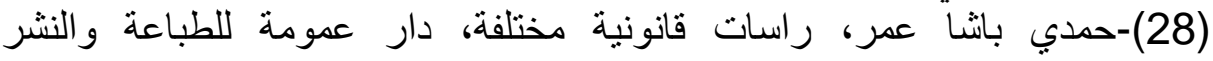

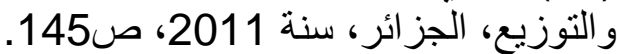
(29)-القانون 11/84 المؤرخ في 1984/06/09 المتضمن قانئنون الأسرة، ج.ر، رقم

(30)- دسنور 1989 الصادر بالمرسوم الرئاسي 218/89 في 1989/11/28، ج

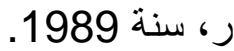
(31)- صالح صالحي، نوال بن عمارة، المرجع السابق ،ص 160 (32) (32)-القانون رقم 10/91 المؤرخ في بن عمارة 1991/04/27 المتعلق بالأوقاف، ج.ر، العابف

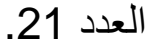

